\title{
RENAL FUNCTION AS MEASURED BY THE ELIMINATION OF FLUIDS, SALT AND NITROGEN, AND THE SPECIFIC GRAVITY OF THE URINE*
}

\author{
HERMAN O. MOSENTHAL, M.D. \\ BALTIMORE
}

During the last few years the study of renal function has largely confined itself to the determination of kidney activity as measured by the quantitative excretion of various dyestuffs and chemicals, either those normally found in the urine or foreign substances which have been fed or injected. By observing the kidney in this manner, notable results have been obtained, especially with phenolsulphonephthalein, lactose, potassium iodid, urea, salt and kreatinin. In most instances, the outcome of intensive study has been the discovery that the elimination of nearly all of these substances may at times be increased quantitatively, in spite of marked renal lesions, or their complications, such as uremia. To supplement such tests, Hedinger and Schlayer ${ }^{1}$ have recently proposed a qualitative test of the mode of urinary function, as measured by the specific gravity, salt and water excretion in two-hourly periods. These authors show how the urinary response to a full dietary containing a reasonable amount of fluids, salt and purins varies in health and disease. They found that the normal and the nephritic individual differ very markedly from one another in the results obtained with the so-called "nephritic test meal." Not only can the absence or presence of impairment of renal function be determined, but likewise its intensity.

The present paper records the results of studies carried out along lines suggested by this work. The test meal has been simplified somewhat, and it appears that the entire procedure, or a part of it, may very well become a valuable routine test for the general practitioner.

This test has now been carried out in more than one hundred cases. The only patients not investigated, in whom renal function should be ascertained, were those suffering from the acute nephritides; of these, such as have been treated in the wards of the hospital during the past winter have been too sick to take food in any qantity, or have been so unmanageable as to preclude the proper collection of specimens. It has been ascertained that the nephritic test meal, when duplicated on

* Submitted for publication July 29, 1915.

* From the Medical Clinic of the Johns Hopkins Hospital, Baltimore.

1. Hedinger and Schlayer: Deutsch. Arch. f. klin. med., 1914, cxiv, 120. 
the same patient, yields identical results, provided the clinical condition has not changed. In several instances triplicate and quadruplicate observations have been made. Lack of space prevents the detailed report of all the findings.

The directions for the nephritic test meal are contained in the following memoranda, given to the nurse in charge of the case in mimeographed form:

NEPHRITIC TEST DIET

For

Date

All food is to be salt free food from the diet kitchen.

Salt for each meal will be furnished in weighed amounts.*

All food or fiuid not taken must be weighed or measured after meals and charted in the spaces beloze.

Allow no food or fluid of any kind except at meal times.

Note any mishaps or irregularities that occur in giving the diet or collecting the specimens.

Breakfast, 8 a. $\mathrm{m}$.

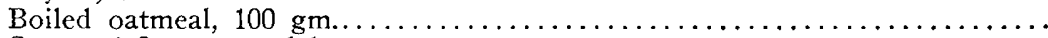

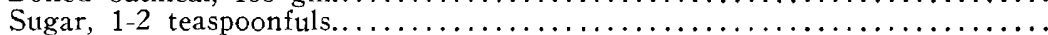

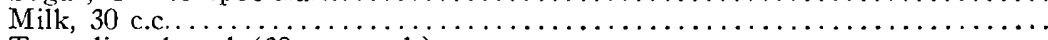

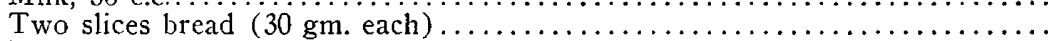

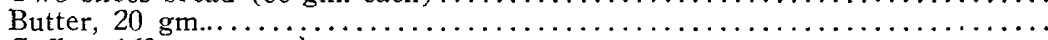

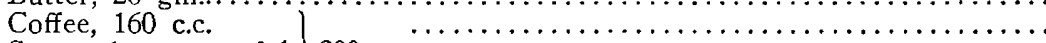

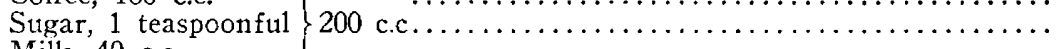

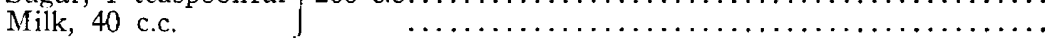

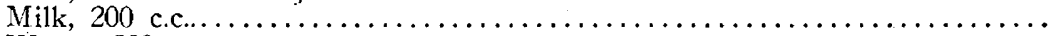

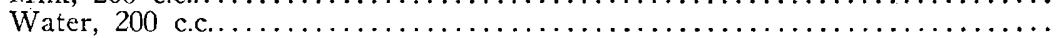

Dinner, 12 Noon.

Meat soup, 180 c.c.

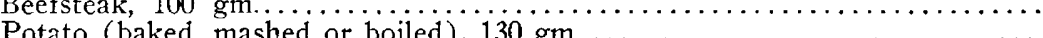

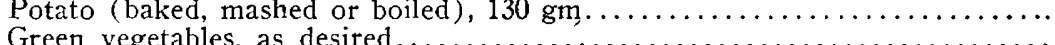

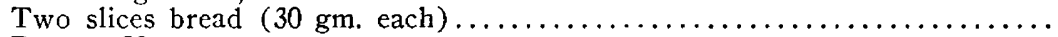

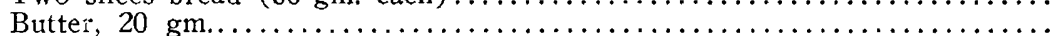

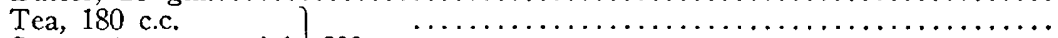

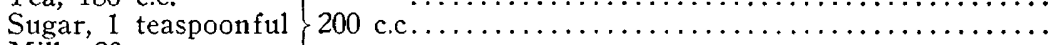

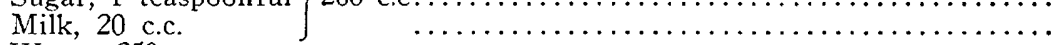

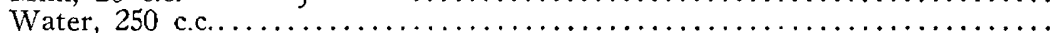

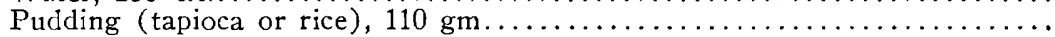

Supper, 5 p. m.

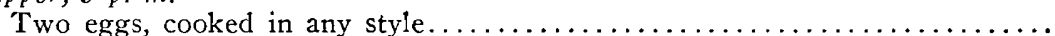

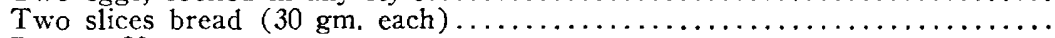

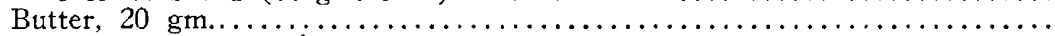

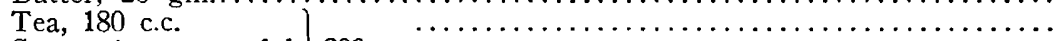

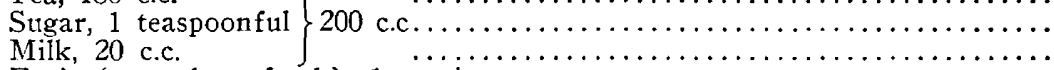

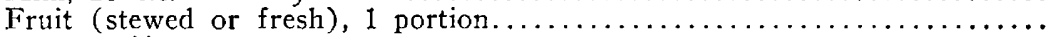

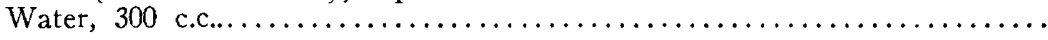

$8 a$. $m$-No food or fluid is to be given during the night or until 8 o'clock the next morning (after voiding), when the regular diet is resumed.

Patient is to empty bladder at $8 \mathrm{a}$. $\mathrm{m}$. and at the end of each period, as indicated below. The specimens are to be collected for the following periods in properly labeled bottles, to be furnished by the Chemical Division of the Medical Clinic:

* One capsule of salt, containing $2.3 \mathrm{gm}$. of sodium chlorid, is furnished for each meal. The salt which is not consumed is returned to the laboratory, where it is weighed, and the actual amount of salt taken is calculated. 
8 a. m. -10 a. m.; 10 a. m.-12 n. ; 12 n. 2 p. m. ; 2 p. m. -4 p. m. ; 4 p. m.-6 p. m.; 6 p. m. 8 p. m.; 8 p. m. -8 a. m.

Specimens are to be left in ward until called for at $8: 30 \mathrm{a} . \mathrm{m}$. by attendant from the chemical laboratory.

The above dietary contains approximately $13.4 \mathrm{gm}$. of nitrogen, $8.5 \mathrm{gm}$. of salt, 1,760 c.c. of fluid, and a considerable quantity of purin material in the meat, soup, tea and coffee. All these substances act as diuretics, and it is on the mode of excretory response to such stimuli that the present study of renal function depends. Spaces are provided to chart the amounts of food not eaten by the patient, and corresponding allowances can be made in calculating the food intake. It is in no way essential that all the meals should be taken in their entirety, nor that the food should be exactly as indicated. The bill of fare here presented has been designed to adapt itself to the daily food supply furnished by the hospital. In private practice, it would orily be necessary to ask the patient to eat three full meals a day and write down the approximate quantities, as- 1 cup of coffee, 2 slices of toast, 2 tablespoonfuls of oatmeal, etc., in order to be certain that the diet for the day contained a sufficient quantity of the diuretic materials of our ordinary food to make an adequate demand on the kidney to test renal function. It is extremely desirable to insist on the fact that, since the food as found in most households suffices to carry out these tests and the procedure is not a complicated one, it need not be confined to hospitals and patients who can afford private nurses.

A wide variation may be permitted in the above-mentioned directions. Certain others, however, must be followed slavishly, in order to make the outcome of the test yield its maximum result. The urine must be collected punctually every two hours. No solid food or fluid of any kind must be taken between meals, and especial care must be observed that nothing of any kind is eaten or drunk during the night, and that the night specimen is completed before breakfast is tottched. The reason for this is that the normal kidney responds rapidly to fluids ingested, so that within a few hours a marked diuresis occurs. The following observation may serve as an illustration of this previously well-established fact:

Time Interval

6 p. m. 8 p. m.

8 p. m. -10 p. m.

10 p. m. 8 a. m.

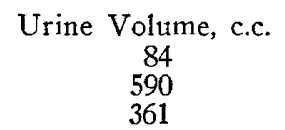

361
Fluid Ingested 7:30 p.m. supper with 1,000 c.c. of water.

In this instance, within two and one-half hours of drinking 1,000 c.c. of water, over 590 c.c. were eliminated, while during the eighthour period following the diuresis, only 361 c.c. of urine were voided.

The volume in cubic centimeters and the specific gravity of each specimen collected are determined: At the outset of the investigation, 
the salt and nitrogen ${ }^{2}$ were measured in each specimen. It soon became apparent, however, that it was necessary to make these calculations only in the total day and night urines. The normal curves show agreement with one another in many respects, and are apparently divergent in others. A considerable number of tests were made on other normal individuals, but yielded nothing further than is known here. The important points to be noted are the following:

1. The characteristics of the day urine.

2. The quantity of water, salt and nitrogen excreted in twentyfour hours.

3. The characteristics of the night urine.

These will be taken up in detail. The phenomena to be observed by means of the test meal may be obtained from specimens passed from day to day, and in patients who are involuntary or irrational, such piecemeal studies may become necessary. Although these have the disadvantage of being long drawn out and usually incomplete, it is surprising how many valuable data may be gleaned in this way, if the points to be noted are kept in mind.

THE NORMAL URINARY RESPONSE TO THE NEPHRITIC TEST MEAL

This is seen in Charts 1,2 , and 3 and Tables 1, 2, and 3. These three examples differ from one another in that the first subject is putting out an approximately normal quantity of fluid in relation to the amount of solids excreted; the second an abnormally large volume of urine (this individual, as a rule, took no tea or coffee and very little meat; the unaccustomed dose of purins of the test meal dietary, therefore, probably produced this great diuresis); the third, a subnormal quantity (a diminished amount of fluids being taken to note this effect). It should be borne in mind that the response to the nephritic test meal in normal individuals is practically always as in Charts 1 or 2. The type in Chart 3 may serve as a control for those pathological cases in which only a small amount of fluid is excreted. The facts to be noted are as follows:

In order to make the results of the test comprehensible at a glance, a graphic representation of the findings has been adopted, as shown in the accompanying charts (Charts 1 to 20 inclusive).

Explanation of the Charts.-Each chart is divided by two horizontal lines into three tiers. The lowest of these gives the figures for water and specific

2. The salt was estimated by the Volhardt method, nitrogen by the Kjeldaht process. Where more extensive laboratory facilities are not at hand, the method of Strauss, as advocated by Bayne-Jones (The Archives Int. Med., 1913, xii, 90) for chlorids, and the hypobromid determination for urea will yield results that are easily obtained and are perfectly adequate from a practical point of view. 
gravity, the middle for nitrogen and the upper for sodium chlorid. Each is further divided by a central vertical line into right and left halves. The left half, with its scale at the extreme left, contains six columns for the two-hourly specimens collected between $8 \mathrm{a}$. $\mathrm{m}$. and $8 \mathrm{p}$. m. Each column represents absolute values. The right half is read by the scale at the extreme right, whose divisions are usually equivalent to one-tenth of those on the left, but rarely, as in Chart 2, to one-fifth, to bring unusual figures within the compass of the chart. The columns of this right half are two pairs, separated by a space. The central pair represents the total night and the total day twelve-hour figures for volume, nitrogen and sodium chlorid, night in solid black and day in oblique hatching at its right. The pair at the extreme right represent intake and output for the whole twenty-four hours, intake at the left in vertical, output at the right in cross or oblique hatching The dots joined by continuous lines crossing each tier from left to right indicate the specific gravity and the percentage concentrations of nitrogen and sodium chlorid, respectively, and are read from the scale at the left.

\section{Table 1.-Normal Reaction to Nephritic Test Meal}

\begin{tabular}{|c|c|c|c|c|c|c|}
\hline \multirow{8}{*}{$\begin{array}{c}\text { Time of Day } \\
8-10 \\
10-12 \\
12-2 \\
2-4 \\
4-6 \\
6-8\end{array}$} & \multirow{2}{*}{$\begin{array}{l}\text { Urine } \\
\text { c.c. }\end{array}$} & \multirow[b]{2}{*}{ Sp. Gr. } & \multicolumn{2}{|c|}{-Sodium Chlorid $\longrightarrow$} & \multicolumn{2}{|c|}{$\neg$ Nitrogen $\longrightarrow$} \\
\hline & & & Per Cent. & $\mathrm{gm}$. & Per Cent. & $\mathrm{gm}$. \\
\hline & 153 & 1.016 & 1.32 & 2.02 & 0.89 & 1.26 \\
\hline & 156 & 1.019 & 1.25 & 1.95 & 0.74 & 1.15 \\
\hline & 194 & 1.0 & 0.64 & 1.24 & 0.59 & 1.14 \\
\hline & 260 & 1.01 & 0.77 & 2. & 0.56 & 1.46 \\
\hline & 114 & 1.0 & 0.9 & & 0.95 & 1.08 \\
\hline & 238 & 1.010 & 0.43 & 1.0 & 0.52 & 1.23 \\
\hline Total day & 1,115 & & & 9.3 & & 7.32 \\
\hline Night, 8-8 & 375 & 1.020 & 0.63 & 2.36 & 1.23 & 4.61 \\
\hline Total 24 hours & 1,490 & & $\cdots$ & 11.72 & $\ldots$ & 11.93 \\
\hline ntak & & ... & $\cdots$ & 8.5 & $\cdots$ & 13.4 \\
\hline Balance ... & +270 & . & $\ldots$ & -3.22 & 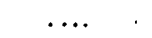 & 1.47 \\
\hline
\end{tabular}

Impression (the figures correspond with Chart 1): Normal reaction to the nephritic test meal. Note the variations occurring in the fluid output, and the specific gravity, which are in inverse ratio; the night urine, which is small in amount and shows a high specific gravity and a high percentage of nitrogen; and the approximately normal output of water, salt and nitrogen in twentyfour-hours.

TABlE 2.-Normal Reaction to Nephritic Test Meal

\begin{tabular}{|c|c|c|c|c|c|c|}
\hline \multirow{7}{*}{$\begin{array}{c}\text { Time of Day } \\
8-10 \\
10-12 \\
12-2 \\
2-4 \\
4-6 \\
6-8\end{array}$} & \multirow{2}{*}{$\begin{array}{l}\text { Urine } \\
\text { c.c. }\end{array}$} & & \multicolumn{2}{|c|}{$\neg$ Sodium Chlorid $\longrightarrow$} & \multicolumn{2}{|c|}{$\longrightarrow$ Nitrogen $\longrightarrow$} \\
\hline & & & Per Cent. & gm. & Per Cent. & gm. \\
\hline & 482 & 1.010 & & & & \\
\hline & 244 & 1.019 & & & & \\
\hline & 290 & 1.010 & & & & \\
\hline & 120 & 1.017 & & - & & \\
\hline & 420 & 1.007 & & & & \\
\hline Total day & 1,796 & & 0.66 & 11.84 & 0.41 & 7.36 \\
\hline Night, $10-8$ & 352 & 1.017 & 0.58 & 2.16 & 1.20 & 4.22 \\
\hline Total 24 hour & 2,148 & & & 14.00 & & 11.58 \\
\hline & 1,760 & ...... & $\ldots$ & 8.50 & .... & 13.40 \\
\hline Balance & -388 & . & $\ldots$ & -5.50 & & 1.82 \\
\hline
\end{tabular}

Impression (the figures correspond with Chart 2): Normal reaction to the nephritic test meal. In this case, polyuria is evident. This is probably due to the reaction in an individual who is accustomed to a bland diet and not to the quantities of salt and purins taken with the test meal. 
TABLE 3.-Normal Reaction to Nephritic Test Meal

\begin{tabular}{|c|c|c|c|c|c|c|}
\hline \multirow{9}{*}{$\begin{array}{c}\text { Time of Day } \\
8-10 \\
10-12 \\
12-2 \\
2-4 \\
4-6 \\
6-8 \\
8-10\end{array}$} & \multirow{2}{*}{$\begin{array}{c}\text { Urine } \\
\text { c.c. }\end{array}$} & \multirow[b]{2}{*}{ Sp. Gr. } & \multicolumn{2}{|c|}{$\tau^{\text {Sodium Chlorid }}$} & \multicolumn{2}{|c|}{$r-$ Nitrogen $\longrightarrow$} \\
\hline & & & Per Cent. & $\mathrm{gm}$. & Per Cent. & $\mathrm{gm}$. \\
\hline & 90 & 1.026 & 1.23 & 1.11 & 1.39 & 1.25 \\
\hline & 78 & 1.027 & 1.29 & 1.0 & 1.58 & 1.24 \\
\hline & 114 & 1.027 & 1.27 & 1.45 & 1.30 & 1.48 \\
\hline & 75 & 1.0 & 0.97 & & 1.77 & 1.33 \\
\hline & 85 & 1.030 & 1.20 & 1. & 1.66 & 1. \\
\hline & 104 & 1.028 & 1.06 & 1.1 & 1.52 & 1.5 \\
\hline & 88 & 1.024 & 0.83 & 0.7 & 1.37 & 1.20 \\
\hline Total d & 634 & & & 7.1 & & 9.50 \\
\hline Night, & 290 & 1.027 & 0.73 & 2.12 & 2.07 & 6.00 \\
\hline Total 24 hours & 924 & $\cdots$ & & 9.26 & $\cdots$ & 15.50 \\
\hline Int & 1,100 & .... & $\cdots$ & 9.00 & $\ldots$ & 16.00 \\
\hline & & & & 0.26 & & \\
\hline
\end{tabular}

Impression (the figures correspond to Chart 3): Normal reaction to the nephritic test meal. In this test the fluid was limited and the solid food increased, so as to produce a concentrated urine, as occurs in myocardial decompensation. The characteristics of the normal response, rise of urine volume after each meal, the variation of specific gravity, the small volume of night urine with a high concentration of nitrogen and high specific gravity, and an approximate balance of fluid, salt and nitrogen, are all present in spite of the restrictions imposed. (In this case supper was taken at $7 \mathrm{p} . \mathrm{m}$. The collections of night urine were, therefore, begun at $10 \mathrm{p} . \mathrm{m}$. instead of at $8 \mathrm{p} . \mathrm{m}$.)

1. The Day Urine.-This shows a rhythmical response to each meal in that the quantity of fluid increases at these periods. This is well shown in Chart 3 ; in Charts 1 and 2 certain irregularities in the diuresis following food ingestion are seen. In Chart 1 there is no distinct polyuria after breakfast and that after the mid-day meal occurs late. A similar delayed polyuria is found on Chart 2. The diuretic response to each meal in the two-hourly periods was not as constantly present as Hedinger and Schlayer found it to be. In fact, at times it is almost entirely suppressed, as is seen in the following instance, in which the rise of urine after supper is distinct, the other responses being masked or absent:

$\begin{array}{lcccccc}\text { Time of day } \ldots \ldots \ldots \ldots \ldots & * 8.10 & 10-12 & * 12-2 & 2-4 & 4 * 6 & 6-8 \\ \text { Volume of urine, c.c. } \ldots \ldots & 118 & 146 & 157 & 180 & 170 & 261\end{array}$

* Indicates the meal hours.

Because of the irregularity of this symptom in normal cases, not very much stress has been laid on its absence in interpreting pathological urines. However, a fixed or constant two-hourly output has proved itself to be of considerable significance in interpreting renal function in some patients.

The specific gravity of the two-hourly specimens is not fixed, but varies inversely to the volume of urine; this is not as markedly the case in Chart 3, where the induced oliguria requires a urine of moderately constant high specific gravity in order to eliminate the required quan- 
tity of solids. However, even in this case, the variations in specific gravity are by no means confined within one or two points, as they are in many of the pathological specimens. Table 4 gives a summary of these observations:

TABLE 4.-Summary of Specific Gravity Observations in Normal INDIVIDUALS

$\begin{array}{cccc}\text { Case } & \text { Maximum } & \text { Minimum } & \text { Difference } \\ 1 & 1.020 & 1.010 & 10 \\ 2 & 1.019 & 1.007 & 12 \\ 3 & 1.031 & 1.024 & 7 \\ 4 & 1.019 & 1.009 & 10 \\ 5 & 1.020 & 1.007 & 13 \\ 6 & 1.025 & 1.005 & 20 \\ 7 & 1.023 & 1.010 & 13 \\ 8 & 1.018 & 1.008 & 10 \\ 9 & 1.018 & 1.007 & 11 \\ 10 & 1.019 & 1.007 & 12 \\ 11 & 1.026 & 1.014 & 12 \\ 12 & 1.030 & 1.010 & 20\end{array}$

The maximum and minimum figures for urinary specific gravity, as found in the specimens collected in two-hour periods during the day from normal individuals on a nephritic test diet. Note the marked variation between the highest and lowest observations in each instance. The lowest variation occurs in Case 3 (see Table 3); this is due to the fact that in this individual water intake was much restricted.

2. The Quantity of Water, Salt and Nitrogen Excreted in TwentyFour Hours.-Normally the urinary fluid output should be about 400 c.c. less than the intake, to allow for the excretion of water by the lungs, skin and intestines. About 90 per cent. of the nitrogen ingested should be found in the urine, the remainder passing out in the feces. The sodium chlorid as found in the urine represents practically the total excretion of this substance except in cases of diarrhea. These statements hold true for carefully regulated mctabolism studies carried on over several days, but it must be remembered that the previous habits have a very great bearing on tests such as those under consideration here. Thus it has been noted, on comparing Charts 1 and 2, how a full diet produces polyuria in an individual who has been accustomed to very bland food, and furthermore, it is found that a comparatively small amount of urine is produced by an individual who on the previous day has drunk too little fluid to meet his requirements. Various and often easily ascertainable reasons may exist for either retention o1 an excess of excretion, which may lead us to look on these phenomena as presenting no abnormalities. However, they should always be regarded with suspicion and be thoroughly considered in their bearing on the case in question. Vastly more important is the concentration of salt and nitrogen in the urine. A normal kidney can readily concentrate nitrogen and salt above 1 per cent.; an abnormal kidney often 
can not. Therefore, the total quantity of urine and urinary ingredients excreted is to be observed, but particular stress is to be laid on the concentration of nitrogen and salt.

3. The Characteristics of the Night Urine.-Whatever the quantity of urine excreted during the day, it is found that the night specimen varies within very narrow limits. The precautions of not allowing water at night time, previously dwelt on, must be strictly carried out to make this observation of value. In the night urine, as a rule, the concentration of nitrogen and the specific gravity are high. The figures for normals, as given in Table 5, substantiate these statements.

TABLE 5.-Comparison of Night and Day Urines in Normal Individuals

$\begin{array}{ccccc}\text { Case } & \begin{array}{c}\text { Specific } \\ \text { Gravity }\end{array} & \begin{array}{c}\text { Nitrogen } \\ \text { Per Cent. }\end{array} & \begin{array}{c}\text { Volume } \\ \text { c.c. }\end{array} & \begin{array}{c}\text { (12 Hours) } \\ \text { Volume, c.c. }\end{array} \\ 1 & 1.020 & 1.23 & 375 & 1,105 \\ 2 & 1.017 & 1.20 & 352 & 1,796 \\ 3 & 1.027 & 2.07 & 290 & 634 \\ 4 & 1.019 & 1.12 & 350 & 1,032 \\ 5 & 1.018 & 1.03 & 390 & 1,945 \\ 6 & 1.018 & 1.43 & 361 & 1,413 \\ 7 & 1.019 & 1.14 & 355 & 2,156 \\ 8 & 1.018 & 1.08 & 402 & 2.446 \\ 9 & 1.026 & 1.42 & 277 & 866 \\ 10 & 1.030 & 1.58 & 210 & 1,496 \\ 11 & 1.029 & 1.85 & 213 & 468 \\ 12 & 1.025 & 1.23 & 248 & 861\end{array}$

The nitrogen percentage, specific gravity and volume for the night urines of normal individuals on a nephritic test diet. Note the high percentage of nitrogen, high specific gravity and the small volume of urine, as compared to the day specimen.

The most important points to be observed in the urine of normal individuals on the nephritic test meal are:

1. Variations in the specific gravity of the urine specimens (usually 10 points or more; in cases of diminished water intake and oliguria, the variations may be somewhat less).

2. The balance between the output and intake of salt, nitrogen and fluids. This should be approximately equal.

3. A night urine high in specific gravity (1.016, but 1.sually 1.018 or higher), high in its percentage of nitrogen (above 1 per cent.) and small in amount (400 c.c. or less), regardless of the quantity of fluid ingested or the amount of urine voided during the day.

THE URINARY RESPONSE TO THE TEST MEAL IN DISEASE

The individual factors will be first discussed and then applied to special cases. 
1. The Day Urine.--Koranyi ${ }^{3}$ summarized the essential findings of his own and others' work in relation to these problems. These are in full accord with the facts as substantiated by Hedinger and Schlayer ${ }^{1}$ and in the present observations. The kidney expresses its diminished power to functionate by a fixation of its concentration. The normal kidney yields a urine of medium, low or high specific gravity (Table 4) according to the proportion of fluids and solids that must be excreted in order to maintain the composition of the body fluids at a constant level. The diseased kidney, on the other hand, loses this flexibility and the power to answer a demand for a more concentrated or more dilute urine no longer exists. This condition Koranyi has spoken of as hyposthenuria. Koranyi emphasizes the fact, which is usually not sufficiently appreciated, that the power to excrete a more dilute urine is lost, as well as that to concentrate (Chart 6). Such a fixation of specific gravity appears when the kidney is the seat of a nephritis, but the fact must not be lost sight of that extrarenal factors may damage kidney function to an equal extent. This fixation of specific gravity occurs in nephritis, pyelitis, cystitis associated with prostatic

TABLE 6.-Specific Gravity of Urines Collected in Two-Hourly Periods Case

Degrees of

\begin{tabular}{|c|c|c|c|c|c|c|}
\hline Case & \multicolumn{2}{|c|}{-Specific } & \multicolumn{3}{|c|}{ Gravity*- } & Variation in \\
\hline Normal (Chart 1) & 1619 & 12 & 14 & 20 & 10 & 10 \\
\hline Incipient primary contracted kidney & $09 \quad 14$ & 09 & 10 & 14 & 06 & 8 \\
\hline Incipient primary contracted kidney. & 1809 & 16 & 22 & 13 & 10 & 11 \\
\hline Advancing primary contracted kidney & $18 \quad 17$ & 13 & 13 & 13 & 15 & 5 \\
\hline Advancing primary contracted kidney & 1920 & 20 & 20 & 21 & 20 & 2 \\
\hline Advanced primary contracted kidney.... & $11 \quad 11$ & 10 & 11 & 11 & 11 & 1 \\
\hline Advanced primary contracted kidney.... & 1211 & 11 & 11 & 12 & 13 & 2 \\
\hline Advanced primary contracted kidney.... & $10 \quad 09$ & 10 & 09 & 09 & 10 & 1 \\
\hline Advanced primary contracted kidney..... & 0506 & 07 & 08 & & 08 & 3 \\
\hline Incipient chronic diffuse nephritis.. & 25 & 24 & 33 & 28 & 30 & 9 \\
\hline Incipient chronic diffuse nephritis. & $09 \quad 16$ & 15 & 17 & 12 & 07 & 10 \\
\hline Advanced chronic diffuse nephritis. & $12 \quad 11$ & 14 & 11 & 13 & 11 & 3 \\
\hline Secondary contracted kidney $\ldots \ldots \ldots \ldots$ & $09 \quad 10$ & 12 & 10 & 12 & 10 & 3 \\
\hline $\begin{array}{l}\text { Congested kidney; myocardial decom- } \\
\text { pensation marked }\end{array}$ & 20 & 10 & 18 & 20 & 21 & 3 \\
\hline Congested kidney; moderate myocardial & & & & & & \\
\hline decompensation..$\ldots \ldots \ldots \ldots \ldots \ldots \ldots$ & $25 \quad 24$ & 24 & 25 & 24 & 21 & 4 \\
\hline $\begin{array}{c}\text { Congested kidney } ; \text { cardiac compensation; } \\
\text { losing edema } \ldots \ldots \ldots \ldots \ldots \ldots \ldots \ldots \ldots\end{array}$ & 1215 & 10 & 15 & 13 & 10 & 5 \\
\hline Congested kidney $;$ cardiac compensation; & & & & & & \\
\hline & 0506 & 11 & 09 & 09 & 10 & 5 \\
\hline Polycystic kidney & 1010 & 10 & 11 & 10 & 10 & 1 \\
\hline Marked anemia & 1010 & 10 & 10 & 10 & 11 & 1 \\
\hline Diabetes insipidus & $04 \quad 04$ & 06 & 04 & 04 & 04 & 2 \\
\hline Cystitis, pyelitis, prostatic hypertrophy.. & 1010 & 10 & 10 & 11 & 11 & 1 \\
\hline Pyonephrosis ... & $11 \quad 12$ & 12 & 13 & 12 & 12 & 2 \\
\hline
\end{tabular}

* Variations of specific gravity in the day urine collected in two-hourly intervals. Note the fixed specific gravity of the severe cases of nephritis. Only the last two figures of each reading are given.

3. Koranyi and Richter: "Physiakalische Chemie und Medizin," Leipzig, 1908, ii, 136-152. 
hypertrophy, hydronephrosis, pyonephrosis, polycystic kidneys, renal congestion due to cardiac disease, both in the stage of decompensation and in the early stages of recovering compensation, diabetes insipidus, severe anemias, and possibly in other conditions.

Table 6 shows the specific gravities of some of these urines, as found in the two-hourly diurnal periods.

The figures in Table 6 bear out what has been said, and demonstrate how extreme a fixation of urinary concentration may become. In this connection the data given in Table 7 are also of interest, showing how a low specific gravity may remain a fixture from day to day in nephritis, in the diurnal as well as the nocturnal specimens:

E. F. (Medical No. 33757), male, aged 36. Albumin was discovered in the urine seventeen years ago. For five years there has been polyuria and polydipsia; for two years, failing vision. There is moderate thickening of all the peripheral arteries. The cardiac impulse is forcible in the fifth interspace, $12.5 \mathrm{~cm}$. to the left of the median line, indicating some hypertrophy of the heart muscle. There is no edema, nor are there other signs of myocardial insufficiency. The systolic blood pressure varies between 210 and $195 \mathrm{~mm}$. of mercury. The eyegrounds show marked albuminuric retinitis. The urine is large in amount, constantly low in specific gravity, contains about $1 \mathrm{gm}$. of albumin per liter, and on microscopic examination yields a few hyaline casts. The phenolsulphonephthalein excretion is 22 per cent. in two hours. The nonprotein nitrogen of the blood is $59 \mathrm{mg}$. per 100 c.c. The diagnosis is an advanced degree of chronic diffuse nephritis (secondary contracted kidney).

The night and day urines followed over a considerable period gave the figures shown in Table 7.

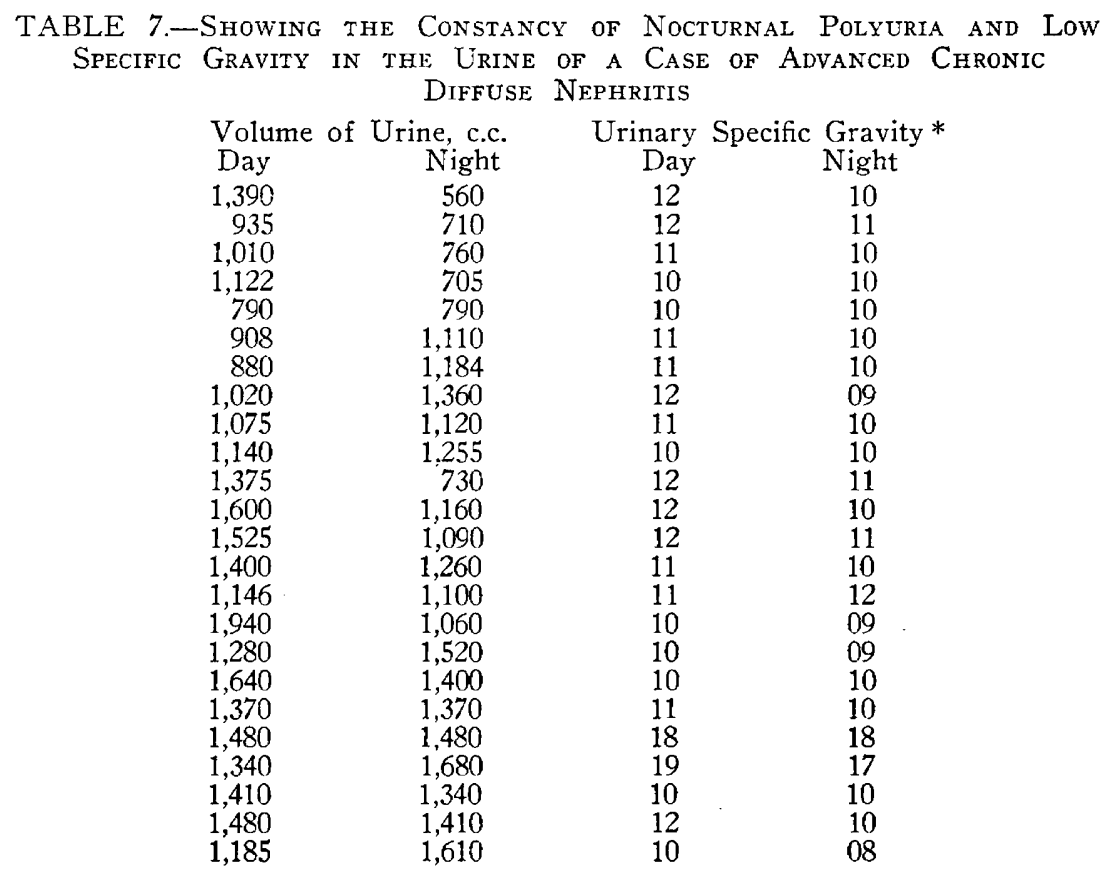

* Only two last figures are given. 
On two days (towards the lower portion of the table) the specific gravity rose to about 1.018 . This is the only case of advanced nephritis with a tendency to low specific gravity in which a variation of this kind was noted. In chronic diffuse nephritis, such changes in the level of concentration are common, but they occur gradually, being associated with definite phases of the disease. (Compare Charts 17 and 18.) Von Noorden ${ }^{4}$ contends that all cases of contracted kidney pass a low specific gravity urine because of polydipsia, that they all concentrate the urine in some specimen during a part of the clay, and that it is wrong to assume an obligatory hyposthenuria on their part. The figures of Table 6 indicate no variability in the day urine of these cases and all attempts to limit the water of such individuals have been found to be impracticable. The impression gained from these studies is that pathologic lesions of the kidney are responsible for the low fixed specific gravity of the urine and that, with rare exceptions, when once established it remains constantly low.

The level of the fixed specific gravity changes under certain conditions. Besides the cases of chronic diffuse nephritis just referred to, this is noted in myocardial insufficiency, in which it is constantly high (Charts 13 and 14), until compensation is established, when it assumes a lower level (Chart 15). Even then, when all edema has disappeared and it would be expected that the renal functions had returned to normal, this anomaly of urinary secretion, a low moderately fixed specific gravity, persists (Chart 16). It accentuates the fact that functional and anatomical integrity are not synonymous terms.

The water excretion is very often found to remain markedly constant in quantity in the two-hourly periods, as does the level of the specific gravity (Charts 6,10,11 and 12). This factor may be of value in estimating renal function; however, it was found to be of much less significance than the specific gravity in the tests here reported, and consequently the greatest stress has been put on the latter. The salt and nitrogen percentages of the urine exhibited the same tendency to a constancy in their percentage values as did the specific gravity figures. (Compare Charts 1,2, and 3 of the normal individuals with Charts 7 and 11). Here, again, nothing was added to the information gained from the specific gravity, and consequently, in order to simplify the whole procedure to its utmost, these determinations were omitted for the two-hourly specimens and ascertained only for the total day and night urines.

2. The Quantity of Water, Salt and Nitrogen Eliminated in Tacnty-Four Hours.-Impaired renal function may be associated with

4. Von Noorden: Handbuch der Pathologie des Staffwechsels. Berlin, 1906, i, 994. 
a retention of one or all of these elements. The cardiac and renal cases have been rather fully investigated in this connection and, as a result, certain definite conclusions may be formulated in regard to them.

When there is passive congestion of the kidney due to myocardial insufficiency, the amounts of water and sodium chlorid eliminated are much diminished, while the nitrogen excretion remains approximately normal. An extreme case of this kind was found in L. (Medical No. 33177), who, on autopsy, proved to have cardiac decompensation, brought on by a severe grade of myocarditis, thromboses of the coronary arteries and infarcts in the myocardium; the kidneys showed congestion only; urinary tests in this patient y:elded the results shown in Table 8.

TABle 8.-Results of Urinary Tests in Patient $L$. (Marked Myocardial Insufficiency)

\begin{tabular}{|c|c|c|c|c|c|c|}
\hline & Urine & Specific & -Sodium & oridh & -Nitro & \\
\hline Day & Volume, c.c. & Gravity & Per Cent. & $\mathrm{gm}$. & Per Cent. & gm. \\
\hline & 850 & 1.022 & 0.02 & 0.17 & 1.76 & 14.9 \\
\hline 2 & 770 & 1.022 & 0.04 & 0.31 & 1.74 & \\
\hline 3 & 545 & 1.025 & 0.03 & 0.16 & 1.56 & .5 \\
\hline 4 & 420 & 1.025 & 0.02 & 0.08 & 1.56 & 6 \\
\hline
\end{tabular}

In such instances, the minimal concentration of salt and the high percentage of nitrogen indicate the very limited ability of the kidney to eliminate sodium chlorid, while the power to excrete nitrogen remains normal, provided a reasonable amount of urine is secreted.

Milder grades of myocardial decompensation yield similar results, though the sodium chlorid elimination is not diminished to the same extent. This is well shown in Charts 13 arid 14. These and two similar cases may be summarized in Table 9.

TABle 9.-Summary of Urine Tests in Cases of Myocardial DeCOMPENSATION

\begin{tabular}{|c|c|c|c|c|c|c|}
\hline & Urine & Specific & $\neg$ Sodium & orid $\longrightarrow$ & - Nitro & \\
\hline Case & Volume, c.c. & Gravity & Per Cent. & $\mathrm{gm}$. & Per Cent. & $g$ \\
\hline 1 & -540 & 1.020 & 0.25 & 1.34 & 1.44 & 7.78 \\
\hline 2 & 573 & 1.019 & 0.28 & 1.6 & 1.76 & 10.08 \\
\hline & 484 & 1.0 & 0.52 & & 1.58 & \\
\hline & 44 & 1.018 & 0.61 & 272 & 1.38 & \\
\hline
\end{tabular}

The low percentage of salt and the oliguria, as compared to the high concentration of nitrogen, are very strikingly shown in Table 9.

With recovery of cardiac compensation, the excretion of salt and water is much improved, as is seen in Charts 15 and 16. Many of these individuals, however, do not excrete the salt of their dietary completely. Retaining a small amount of salt on each day, they finally develop a marked edema. Under these circumstances, the curious picture often presents itself of a patient with general subcutaneous 
edema, and possibly a transudate in one or the other of the body cavities, without dyspnea, marked cyanosis, or other signs of myocardial insufficiency. On the removal of salt from the food, the edema again disappears rapidly. Not all cases exhibit this inability to excrete sodium chlorid. Except by trial, there seems to be no way of distinguishing those that will from those that will not tolerate salt. It is a very important point, from the therapeitic side, and as much stress should be laid on the reștriction of salt in these cases as on the limitation of fluids.

In nephritis, two distinct types of excretion are found:

1. Salt retention not associated with deficient nitrogen elimination. This is seen in the cases of chronic diffuse (parenchymatous) nephritis. The entire picture has had Widal's name associated with it for a long time. A test meal in a patient of this type yields the results shown in Table 10.

Table 10.-Nephritic Test Meal in a Case of Chronic Diffuse (Parenchymatous) Nephritis

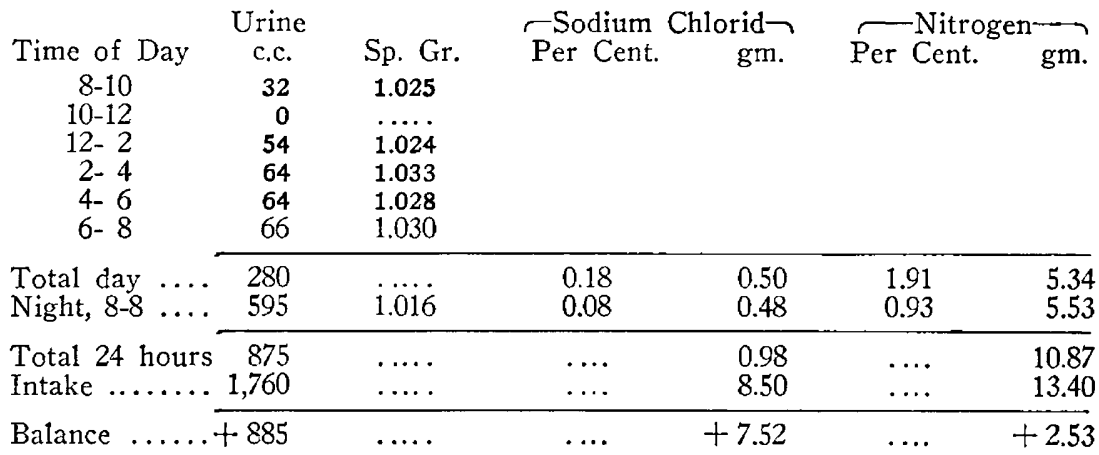

Impression: There is marked salt and water retention; the excretion of nitrogen is adequate. The variations in specific gravity distinguish this case from one of cardiac insufficiency, and indicate that renal function as a whole is not seriously impaired.

With rest and adequate treatment, the power to excrete salt and water is rapidly acquired, and the whole process of renal activity changes. A test meal in the same individual yields an entirely different set of figures under such circumstances (Table 11).

2. In advanced cases of primary or secondary contracted kidney, characterized by hypertension and termination in uremia, the quantities of salt and nitrogen excreted are both diminished. In none of these patients has much improvement in this regard been noted. In observing the urine of hypertensive nephritis, and attempting to couple it with constant clear-cut characteristics, the precaution must be taken to separate the uncomplicated cases from those associated with other 
lesions, such as marked anemia, cardiac insufficiency, or bronchopneumonia. The analyses of the test meals in these individuals, all of them in advanced stages of the disease, are shown in Table 12.

\begin{tabular}{|c|c|c|c|c|c|c|}
\hline TABLE 11.- & JEPHRITIC & $\begin{array}{r}\text { TEST } \\
\text { SoI }\end{array}$ & $\begin{aligned} \text { AL IN } & \text { THE } \\
\text { TIME } & \text { LATER }\end{aligned}$ & SAME CAS & E AS TABLE & 10 \\
\hline Time of Day & $\begin{array}{l}\text { Urine } \\
\text { c.c. }\end{array}$ & Sp. Gr. & $\stackrel{\text { Sodium }}{\text { Per Cent. }}$ & $\begin{array}{c}\text { Chlorid- } \\
\text { gm. }\end{array}$ & $\overbrace{\text { Per Cent. }}^{\text {Nitroge }}$ & $\mathrm{gm}$. \\
\hline $8-10$ & 137 & 1.015 & 0.82 & 1.12 & 0.70 & 0.95 \\
\hline $10-12$ & 148 & 1.0 & 0. & 1. & 0.80 & \\
\hline $12-2$ & 108 & 1.0 & & 0. & 0.79 & \\
\hline $2-4$ & 184 & 1.015 & 0.5 & $1 .($ & 0.79 & \\
\hline & 96 & 1.015 & 0. & 0. & 0.79 & 0.76 \\
\hline $6-8$ & 470 & 1.004 & 0.30 & 1.4 & 0.25 & a \\
\hline ind da & 1,143 & & & 6.02 & & 38 \\
\hline & & 1.010 & 0.34 & 3.26 & 0.38 & \\
\hline otal 24 hour & 2,103 & .. & & 9.28 & & 10.03 \\
\hline & 1,760 &. & & 8.50 & & 13.40 \\
\hline Balanc & -343 & & & -0.78 & & 3.37 \\
\hline
\end{tabular}

Impression: Water and salt are excreted in excess in contrast to previous meal. The polyuria, both during the day and night, and the rather low fixed specific gravity, are due to the fact that this patient is eliminating edema, and must not be confounded with similar curves obtained in case of hypertensive nephritis, where they would indicate a considerable degree of impaired renal function. On physical examination, the two conditions can very easily be distinguished from one another.

TABle 12.-Nitrogen, Salt and Water Excretion in Advanced Uncomplicated Interstitial Nephritis*

\begin{tabular}{|c|c|c|c|c|c|c|}
\hline & Urine & Specific & \multicolumn{2}{|c|}{- Sodium Chlorid- } & \multicolumn{2}{|c|}{-Nitrogen- } \\
\hline Case & Volume, c.c. & Gravity & Per Cent. & $\mathrm{gm}$. & Per Cent. & g \\
\hline 1 & 776 & 1.014 & 0.37 & 2.88 & 0.65 & \\
\hline 2 & 1,28 & 1.0 & 0.2 & 3.6 & 0.52 & \\
\hline 3 & 1,27 & 1.0 & 0. & 5. & 0.49 & \\
\hline 4 & 1,53 & 1.009 & 0. & 5. & 0.42 & \\
\hline 5 & 1,8 & $1.011^{\circ}$ & 0. & & 0.14 & \\
\hline 5 & 1,541 & 1.010 & 0.30 & 4.7 & 0.30 & \\
\hline 7 & 1,665 & 1.009 & 0.12 & 200 & 0.09 & \\
\hline
\end{tabular}

* The approximate intake was 1,760 c.c. of fluid, $8.5 \mathrm{gm}$. of salt and $13.4 \mathrm{gm}$. of nitrogen in each case.

From Table 12 it is clear that the low specific gravity usually attributed to these cases has been found here as well, and that the urinary concentration of salt and nitrogen is so much depressed that there is retention of these substances.

When cases of this kind are complicated by various intercurrent factors, the same degree of impairment in the elimination of salt and water is not found even just before death. Fatal termination in them is hastened by anemia, heart failure, bronchopneumonia, etc., and hence the involvement of renal function does not have an opportunity to develop to its full extent. It may be that the lack of a uniform 
picture in the urine of uremic patients (and even renal cases less severely affected) may be due to the tendency to place every case of hypertension in this category, regardless of whether any complications be present or not.

In no instance has the combination of nitrogen retention with sufficient salt excretion been met with.

3. The Night Urine.-Since the systematic and thorough observations of Quincke, ${ }^{5}$ it has been recognized that a nocturnal polyuria is a valuable sign of impaired renal function. Throigh these, and the studies of v. Leube, ${ }^{6}$ Runeberg, ${ }^{7}$ Wilson, ${ }^{8}$ Iljisch, ${ }^{9}$ Laspeyres $^{10}$ and Pehu, ${ }^{11}$ it has been shown that a supernormal quantity of urine at night, or nycturia, as it has been termed by Pehu, is significant of a variety of conditions. Acute or chronic nephritis, amyloid kidney, myocardial insufficiency, diabetes mellitus, cystitis, prostatic hypertrophy, and the excretion of edema, have all been found at times to produce a nycturia.

It is often noted in patients' histories that urine is voided two, three or more times during the night, and yet closer investigation shows this to be a nocturnal pollakiuria, not accompanied by an increase above the normal amount (400 c.c.). In some cases, a urethritis, prostatic hypertrophy or other local source of irritation may be found; in others, constituting a large number, the increased frequency of voiding at night can only be attributed to a nervous habit. Among many investigated with this point in view, the following may serve as an example: The patient complained of voiding four to ten times a night before admission; since entering the hospital he has passed his urine three or more times. In two twenty-four-hour periods the day urine amounted to 742 and 510 c.c. ; the night specimens to 202 and 315 c.c. To interpret the increased frequency of voiding urine at night as signifying a nocturnal polyuria, as is often done, would in such cases lead to an erroneous conclusion.

In the course of these studies, ${ }^{12}$ the impression has been gained that nycturia is frequently one of the earliest symptoms of renal disease

5. Quincke: Arch. f. exper. Path. u. Pharmakol., 1913, xxxii, 211.

6. Von Leube: Deutsch. Arch. f. klin. Med., 1869, v, 372.

7. Runeberg: Deutsch. Arch. f. klin. Med., 1880, xxvi, 211.

8. Wilson: Lancet, London, 1889, I. (67th year), 1299.

9. I1jisch: München. med. Wchnschr., 1896, xciii, 1299.

10. Laspeyres: Deutsch. Arch. f. klin. Med., 1900, lxviii, 175.

11. Pehu: Rev. de méd., 1903, xxiii, 379.

12. In collecting separate night and day specimens, the precautions previously mentioned, that supper be taken three hours before the night urine collection is begun, that no food or fluid be allowed during the night, and that the night specimen be completed before breakfast is eaten, have been strictly observed throughout. 
met with. It may be found when the only other signs of nephritis are a trace of albumin and a few hyalin casts. Thus, in W. (Medical No. 34121 ), a laborer of 23 years, showing a trace of albumin and a moderate number of hyalin and granular casts in the urine, but no other signs of nephritis, the figures shown in Table 13 were obtained after the test meal:

TABLE 13.-Nephritic Test Meal in an Individual with a Slight

Grade of Albuminuria, a Few Casts, but No Other Signs of NePHRITIS

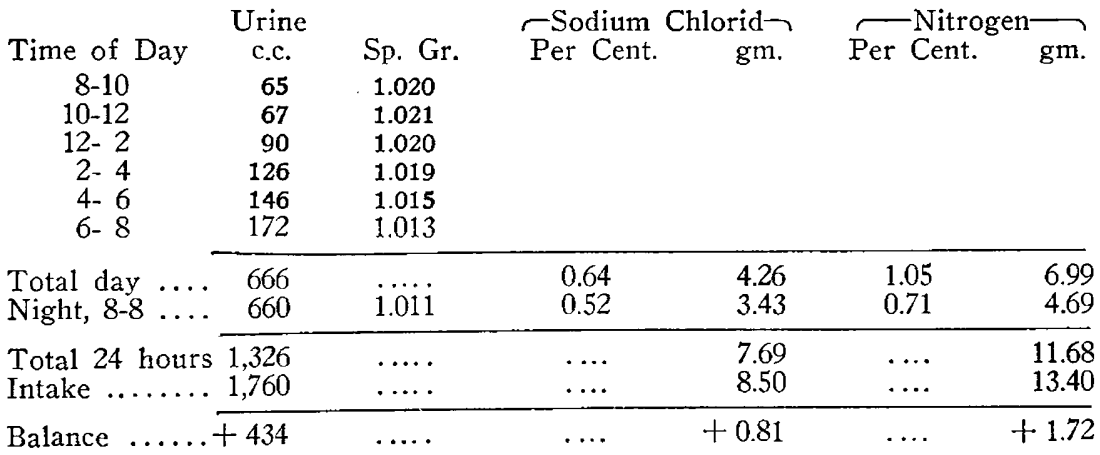

Impression: The concentration of urine, as indicated by the specific gravity and the percentage figures of sodium chlorid and nitrogen, are satisfactorily high. The total amounts of fluids and solids eliminated may also be considered normal. However, the urinary volume and specific gravity do not vary after the ingestion of meals as they should, and the night urine shows a distinct nocturnal polyuria with a low specific gravity. The whole picture, therefore, represents a moderately impaired renal function.

Occasionally, nocturnal polyuria is found in cases in which no organic cause for this phenomenon can be determined. It may be that in these patients an augmented night urine represents a functional change which exhibits itself as the first symptom of a kidney lesion. This is a surmise, and can be proved only by noting the subsequent course of events. One such case is as follows:

S. C. (Medical No. 33538), aged 38, a valet, has had several attacks of acute gout. The patient's joints show signs of the process, which has left permanent damage in the knees and some of the smaller joints of the feet; the urine is

Table 14.-Data in a Case of Nocturnal Polyuria Without DemonSTRABLE Renal InVOLVEMENT

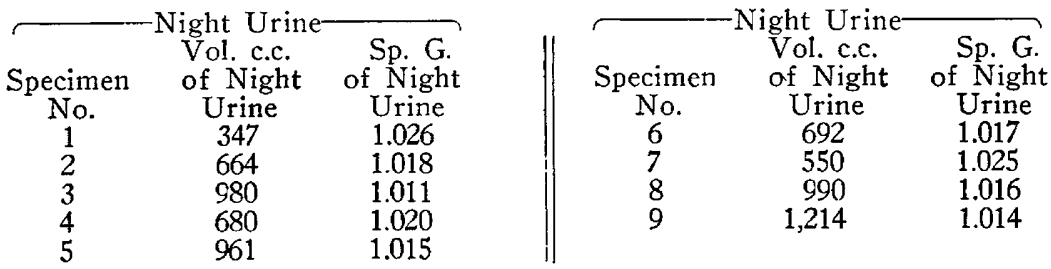


negative for albumin and casts; the systolic blood pressure is 123 ; the phenolsulphonephthalein excretion is 80 per cent. in two hours. No signs of nephritis can be detected, though the frequent association of gout and damage to the kidney are kept in mind. The test meal shows a normal function, except for a nocturnal polyuria. This is duplicated on subsequent nights and the figures in Table 15 are obtained.

With the exception of the first specimen, the volume at night is distinctly increased above the normal (400 c.c.). The specific gravity (except in Specimen 3) is, however, not as low as is usual in pathological night urines. It may well be that in the very earliest stages of diminished renal function the amount of urine is increased without a lowering of the specific gravity. This also goes to show that the low specific gravity need not necessarily follow on the passage of a large volume of urine at night, but depends to some exient on other factors.

TABle 15.-Volume, Specific Gravity and Nitrogen Percentage of the Night Urine in Cases of Chronic Interstitial Nephritis*

\begin{tabular}{|c|c|c|}
\hline Volume & Specific & Per Cent \\
\hline c.c. & Gravity $\dagger$ & Nitrogen \\
\hline 1,273 & 09 & 0.28 \\
\hline 1,140 & 07 & 0.20 \\
\hline 1,140 & 10 & 0.43 \\
\hline 1,110 & 10 & 0.61 \\
\hline 1,080 & 07 & 0.23 \\
\hline 1,010 & 10 & 0.42 \\
\hline 965 & 11 & 0.65 \\
\hline 935 & 10 & 0.00 \\
\hline 875 & 10 & 0.55 \\
\hline 870 & 11 & 0.15 \\
\hline 790 & 10 & \\
\hline 770 & 15 & 07 \\
\hline 715 & 16 & 0.71 \\
\hline 704 & 11 & 0.47 \\
\hline 690 & 13 & 0.57 \\
\hline 660 & 11 & 0.71 \\
\hline 654 & 13 & 0.57 \\
\hline $590 \pm$ & 20 & 1.30 \\
\hline 559 & 12 & 0.92 \\
\hline 557 & 13 & 0.70 \\
\hline
\end{tabular}

\begin{tabular}{|c|c|c|}
\hline Volume & Specific & Per Cent. \\
\hline c.c. & Gravity $\dagger$ & Nitrogen \\
\hline 550 & 10 & 0.63 \\
\hline 546 & 12 & 0.65 \\
\hline 546 & 17 & 0.68 \\
\hline 520 & 13 & 0.63 \\
\hline $510 \ddagger$ & 18 & 1.05 \\
\hline $505^{+}$ & 15 & 0.55 \\
\hline $446+$ & 20 & 1.08 \\
\hline $445^{\circ}$ & 10 & 0.50 \\
\hline 445 & 10 & 0.72 \\
\hline 435 & 16 & 0.51 \\
\hline $425 \div$ & 17 & 0.97 \\
\hline 415 & 15 & 0.76 \\
\hline 395 & 14 & 0.68 \\
\hline 370 & 13 & 0.55 \\
\hline 360 & 11 & 0.87 \\
\hline $355 \S$ & 24 & 0.93 \\
\hline $293 \S$ & 28 & 1.04 \\
\hline $144^{\circ}$ & 19 & 0.87 \\
\hline 94 & 15 & 0.51 \\
\hline
\end{tabular}

* Includes all cases of chronic interstitial nephritis studied, many of them associated with hypertension and arteriosclerosis, but not complicated by myocardial insufficiency, a febrile process, marked anemia, or other intercurrent affection.

$\dagger$ Last two figures only.

\$These cases may be considered as approaching the normal; from the night urine alone, only a very slight degree of impairment of renal function is evident.

$\S$ Normal night urines; both of these cases are taken up in detail further on.

Besides the actual increase in the volume of night urine, changes in the specific gravity and concentration of nitrogen have proved themselves of importance in indicating impaired renal function. In Table 15 a considerable number of instances are given in which the night urine is normal in amount, or approximates the normal, and yet the 
specific gravity findings are low and the concentration of nitrogen does not reach the normal.

It is a well established fact that nitrogen derived from the food is excreted rather slowly, ${ }^{13}$ hence the quantity of nitrogen found in the night urine is disproportionately high. This has been shown to be

TABLE 16.-Types of Cases Other Than Chronic Interstitial Nephritis, Whose Urine Gives Evidence of Abnormal NoCturnal Excretion

1. Chronic diffuse nephritis during

\begin{tabular}{lll}
\hline $\begin{array}{l}\text { Volume } \\
\text { c.c. }\end{array}$ & Night Urine & \\
Specific & Gravity* & Per Cent. \\
Nitrogen
\end{tabular}

(a) Water Retention (edema forma-

tion $) \ldots \ldots \ldots \ldots \ldots \ldots \ldots \ldots \ldots \ldots, 595$

553

367

270

(b) Elimination of edema $\ldots \ldots . .106$

960

960

(c) Water balance (edema elimi-

950 nated)

400

$\begin{array}{ll}16 & 0.93 \\ 16 & 0.62 \\ 20 & 0.88 \\ 30 & \ldots . . \\ 28 & \ldots . . \\ 11 & \ldots .47 \\ 10 & 0.73 \\ 14 & \\ 13 & 0.75 \\ 14 & 1.01 \\ 17 & 1.17\end{array}$

2. Heart disease during

$17 \quad 1.17$

(a) Myocardial decompensation.... 275

(b) Elimination of edema........ 1,340

(c) Water balance (edema eliminated ) $\ldots \ldots \ldots \ldots \ldots \ldots \ldots \ldots \ldots \ldots$

3. Hypertensive nephritis, complicated

4. Severe anemia

1,250

680

256

180

0.84

0.53

0.67

12

0.94

0.68

0.51

1.07

1.12

1.09

0.51

0.52

0.57

0.39

5. Cystitis and hypertrophied prostate gland ...................... 1,395

6. Pyelonephritis

775

7. Polycystic kidney ..................... 1,290

8. Diabetes insipidus $\ldots \ldots \ldots \ldots \ldots \ldots, 594$

* Last two figures only.

13. Lusk: The Science of Nutrition, 1909, p. 120. 
constantly above 1 per cent. in normal subjects, whereas, in Table 15, it is seen how low it has a tendency to become in cases of chronic nephritis, even when there is no nocturnal poiyuria. The value of the specific gravity determinations in the night urine depends on similar principles of loss of power of concentration on the part of the diseased kidney.

Similar disturbances in nocturnal urinary secretion are seen in other conditions besides chronic interstitial nephritis. The list of these diseases is a considerable one (Table 16), and a consideration of them leads to the conclusion that renal function may be impaired, so far as the night urine is concerned, by a variety of factors. These same influences also modify the diurnal character of the urine, and they can be discussed to the greatest advantage in taking up the test meal as an entity.

THE RESUlts WITH COMPLETE NEPHRITIC TEST MEALS

Chronic Interstitial Nephritis (Primary or Secondary Contracted Kidney).--It must be borne in mind in studying renal function by means of a test meal or other procedure that anatomical lesions and changes in physiological activity of the organ need not parallel one another. This is particularly true of incipient nephritis; in advanced stages, when much of the renal parenchyma has been destroyed, divergence between autopsy findings and functional tests or clinical symptoms are far less marked. When only a limited amount of functionating renal tissue remains, the reserve power of the kidney and thus its ability to vary its activity within wide limits, is obviously restricted. It becomes necessary for such quantitatively reduced kidneys to function constantly at their maximum capacity, with the result that the urines secreted scarcely vary in their characteristics from day to day or even from hour to hour.

Examining the test meals of these advanced cases (Table 17, Chart 7), the hyposthenuria, as exhibited in the almost absolute fixation of the percentage figures for salt and nitrogen concentration and the specific gravity (Table 6) show under what continual strain the kidney is laboring to eliminate a sufficient quantity of solids. Even through polyuria it cannot keep pace with the food intake (Table 12). A still greater degree of retention, coupled with a more dilute urine, is seen in Chart 8 (Table 18). Many instances were obtained similar to the former, but only one more marked case of renal insufficiency has thus far been encountered, and that is the one pictured here (Chart 8). Both of these patients died within a few weeks after the test was taken, and the same bad prognosis proved itself correct whenever a test meal curve of this nature was produced. The points 
indicating renal insufficiency in these severe examples of contracted kidney are the following:

1. Markedly fixed and low specific gravity.

2. Diminished output of both salt and nitrogen.

3. Tendency to total polyuria.

4. Night urine showing slight or marked increase in volume; low specific gravity; low concentration of nitrogen.

Table 17.-Reaction to Nephritic Test Meal in Advanced Hypertensive NEPHRITIS

\begin{tabular}{|c|c|c|c|c|c|c|}
\hline \multirow{8}{*}{$\begin{array}{c}\text { Time of Day } \\
8-10 \\
10-12 \\
12-2 \\
2-4 \\
4-6 \\
6-8\end{array}$} & \multirow{2}{*}{$\begin{array}{l}\text { Urine } \\
\text { c.c. }\end{array}$} & \multirow[b]{2}{*}{ Sp. Gr. } & \multicolumn{2}{|c|}{-Sodium Chlorid $\neg$} & \multicolumn{2}{|c|}{$\overbrace{-N i t r o g e n} \longrightarrow$} \\
\hline & & & Per Cent. & $\mathrm{gm}$ & Per Cent. & $\mathrm{gm}$. \\
\hline & 133 & 1.010 & 0.36 & 0.48 & 0.35 & 0.47 \\
\hline & 176 & 1.009 & 0.36 & 0.63 & 0.34 & 0.60 \\
\hline & 156 & 1.010 & 0.32 & 0.50 & 0.35 & 0.5 \\
\hline & 212 & 1.009 & 0.36 & 0.76 & 0.34 & 0.72 \\
\hline & 164 & 1.009 & 0.38 & 0.62 & 0.36 & \\
\hline & 104 & 1.010 & 0.33 & 0.34 & 0.33 & 0.34 \\
\hline Total day & 945 & & & 3.33 & & 3.27 \\
\hline$i \pi h t$ & 590 & 1.010 & 0.34 & 2.01 & 0.38 & 2.24 \\
\hline Total 24 hours & 1,535 & & & 5.34 & & 5.51 \\
\hline Intake ... & 1,510 & $\ldots$. & $\ldots$ & 5.80 & $\ldots$ & 12.20 \\
\hline Balance & -25 &. & ... & 0.46 & $\ldots$ & 5.6 \\
\hline
\end{tabular}

Impression (the figures correspond with Chart 7): Reaction to the nephritic test meal in a case of advanced hypertensive nephritis. There is very marked fixation of the percentage figures for nitrogen and salt concentration and the specific gravity. There is evident nitrogen retention. The salt intake is too low to make it certain that a diminished ability to excrete salt does not exist.

\begin{tabular}{|c|c|c|c|c|c|c|}
\hline \multirow{7}{*}{$\begin{array}{c}\text { Time of Day } \\
8-10 \\
10-12 \\
12-2 \\
2-4 \\
4-6 \\
6-8\end{array}$} & \multicolumn{2}{|c|}{ Urine } & \multicolumn{2}{|c|}{$\neg$ Sodium Chlorid $\longrightarrow$} & \multicolumn{2}{|c|}{-Nitrogen- } \\
\hline & c.c. & Sp. Gr. & Per Cent. & $\mathrm{gm}$. & Per Cent. & $\mathrm{gm}$. \\
\hline & 24 & 1.005 & & & & \\
\hline & 106 & 1.006 & & & & \\
\hline & 82 & 1.007 & & & & \\
\hline & 83 & 1.008 & & & & \\
\hline & 230 & $\ddot{1.008}$ & & & & \\
\hline Total day & 525 & & 0.12 & 0.63 & 0.25 & 1.28 \\
\hline Night, $6-8$ & 1,140 & 1.007 & 0.12 & 1.37 & 0.20 & 2.27 \\
\hline & 1,665 & & & 2.00 & & 3.55 \\
\hline Intake...$\ldots$. & 1,850 & .... & $\cdots$ & 6.00 & $\ldots$ & 13.00 \\
\hline Balance .... & +185 & & $\ldots$ & +4.00 & $\ldots$ & +9.45 \\
\hline
\end{tabular}

Impression (the figures correspond with Chart 8): Reaction to the nephritic test meal in a case of extreme interstitial nephritis. Note the low fixed specific gravity, the retention of salt and nitrogen, and the night urine, which is increased in amount, shows a low specific gravity and a low nitrogen concentration.

Tracing the progress from the normal towards this ultimate stage, patients are found in whom a nocturnal polyuria persists, and yet there is no demonstrable affection of any kind in the kidney. Obser- 
vations on such a case have been previously given in this paper. It is probable that these are the signs of a beginning nephritis exhibiting itself by slight changes in function. On the other hand, normal functional tests may be obtained when albumin and a few hyalin casts exist in the urine and there is a slight rise in blood pressure. An example of this kind is shown in Table 19, Chart 4, where the only

table 19.-Comparatively Normad Renal Function in Early Hypertensive Nephritis

\begin{tabular}{|c|c|c|c|c|c|c|}
\hline \multirow{7}{*}{$\begin{array}{c}\text { Time of Day } \\
8-10 \\
10-12 \\
12-2 \\
2-4 \\
4-6 \\
6-8\end{array}$} & \multirow{2}{*}{$\begin{array}{l}\text { Urine } \\
\text { c.c. }\end{array}$} & \multirow[b]{2}{*}{ Sp. Gr. } & \multicolumn{2}{|c|}{$\neg$ Sodium Chlorid $\longrightarrow$} & \multicolumn{2}{|c|}{$\overbrace{\text { Nitrogen }}$} \\
\hline & & & Per Cent. & $\mathrm{gm}$ & Per Cent. & $\mathrm{gm}$. \\
\hline & 60 & 1.018 & & & & \\
\hline & 140 & 1.009 & & & & \\
\hline & $\begin{array}{r}156 \\
58\end{array}$ & $\begin{array}{l}1.016 \\
1.022\end{array}$ & & & & \\
\hline & 252 & 1.013 & & & & \\
\hline & 122 & 1.010 & & & & \\
\hline Total day .... & 788 & & 0.52 & 4.1 & 0.52 & 4.10 \\
\hline Night, 8-8 & 355 & 1.024 & 0.71 & 2.51 & 0.93 & 3.30 \\
\hline Total 24 hours & 1,143 & $\ldots$ & & 6.61 & & 7.40 \\
\hline Intake... & 1,760 & $\ldots \ldots$ & $\ldots$ & 8.50 & $\ldots$ & 13.40 \\
\hline Balance & 617 & $\ldots$ & ... & +1.89 & $\ldots$ & +6.00 \\
\hline
\end{tabular}

Impression (the figures correspond with Chart 4): Except for a diminished nitrogen output and a slightly lowered nitrogen concentration at night, the response to this nephritic test meal is normal. It indicates a comparatively normal renal function in an early case of hypertensive nephritis.

TABLE 20.-Early Hypertensive Nephritis

\begin{tabular}{|c|c|c|c|c|c|c|}
\hline & Urine & & -Sodium & Chlorid $\longrightarrow$ & -Nitro & $\cdot$ \\
\hline Time of Day & c.c. & Sp. Gr. & Per Cent. & $\mathrm{gm}$. & Per Cent. & $\mathrm{gm}$. \\
\hline $8-10$ & 465 & 1.009 & 0.51 & 2.37 & 0.34 & 1.58 \\
\hline $10-12$ & 102 & 1.014 & 0.62 & 0.63 & 0.77 & 0.79 \\
\hline $12-2$ & 205 & 1.009 & 0.32 & 0.66 & 0.44 & 0.90 \\
\hline $2-4$ & 160 & 1.010 & 0.28 & 0.4 & 0.64 & 1.02 \\
\hline $4-6$ & 116 & 1.014 & 0.48 & 1.5 & 0.80 & \\
\hline $6-8$ & 160 & 1.006 & 0.09 & 0.14 & 0.29 & 0.46 \\
\hline Total day & 1,208 & & & 4.79 & & 5.67 \\
\hline Night, $8-8$ & 935 & 1.010 & 0.33 & 3.08 & 0.50 & 4.67 \\
\hline Total 24 hours & 2,143 & & . & 7.87 & ... & 10.34 \\
\hline Intak & 1,760 & ... & $\ldots$ & 7.50 & $\ldots$ & 13.40 \\
\hline Balance . & -383 & $\ldots$ & $\ldots$ & 0.37 & 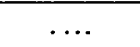 & 3.06 \\
\hline
\end{tabular}

Impression (the figures correspond with Chart 5): The nephritic test meal shows a tendency toward fixation of specific gravity and a distinct nocturnal polyuria in an early case of hypertensive nephritis.

sign of diminished function exists in the slightly lowered concentration of nitrogen $(0.93$ per cent. at night instead of a normal of 1 per cent. or higher), and a moderate nitrogen retention. These changes are so slight as to make it doubtful whether it is not best to classify this 

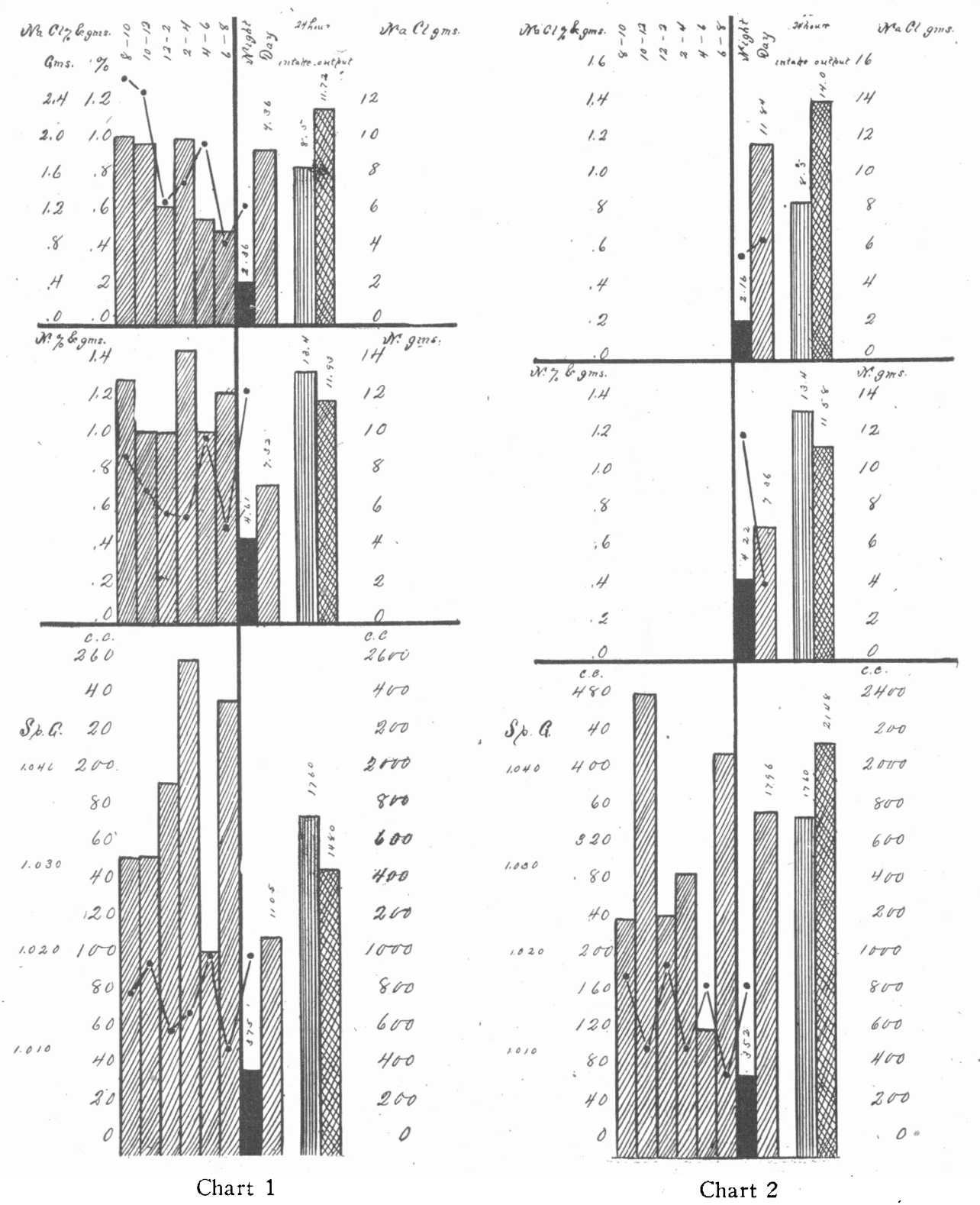

Chart 1.-Normal. Note the variations in specific gravity, high specific gravity and high concentration of nitrogen at night, and approximately normal water, salt and nitrogen output.

Chart 2.-Normal. Same as Chart 1, except that in this case polyuria is evident. This is probably due to the reaction in an individual who is used to a bland diet and not to the quantities of salt and purins given with the nephritic test meal. 


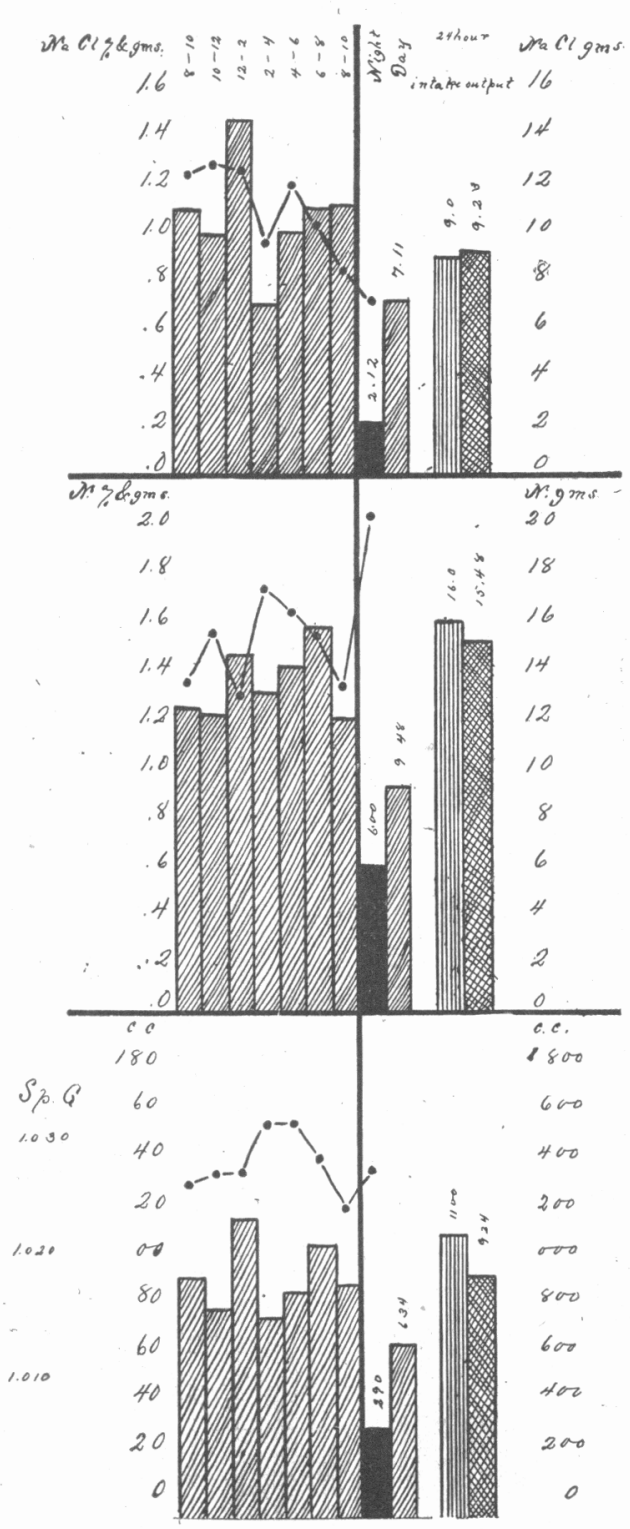

Chart 3

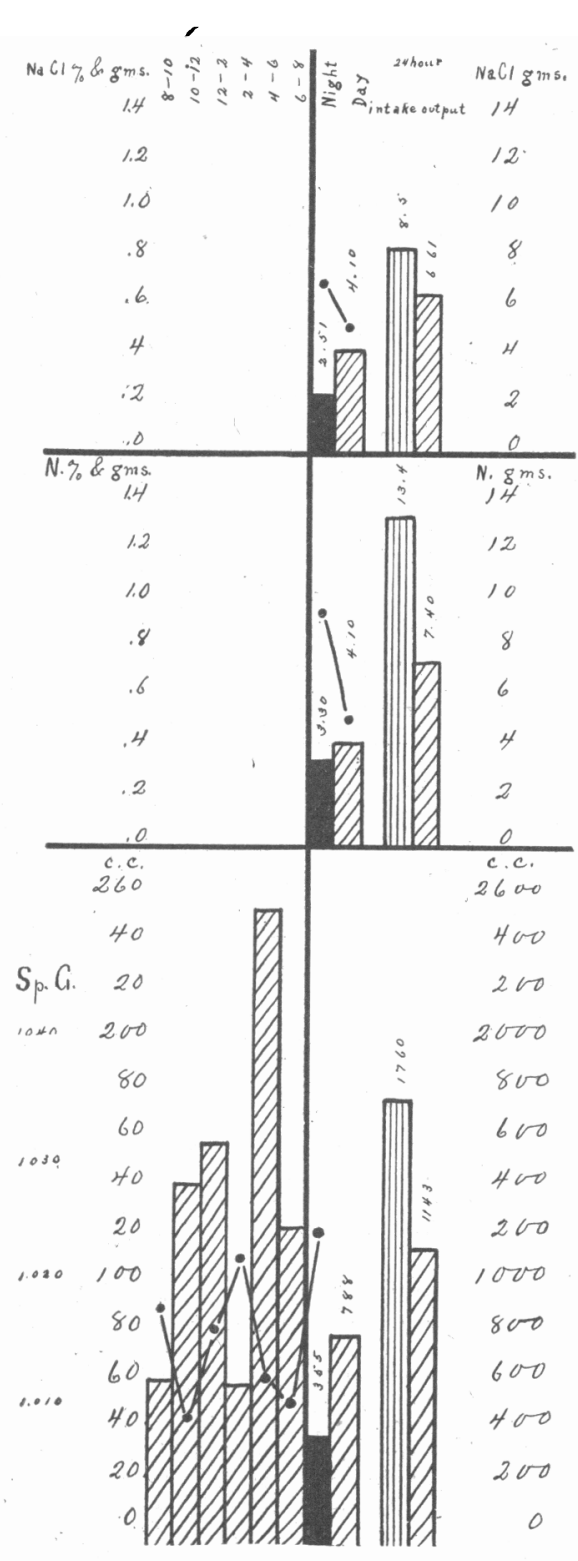

Chart 4

Chart 3.-Normal. Showing the effect of diminished fluid intake.

Chart 4.-Early case of hypertensive nephritis. (Systolic blood pressure 180, when up and about; 145 after rest in bed. Urine shows a trace of albumin and a few hyaline casts.) Nephritic test meal is normal, except for a slight grade of nitrogen retention. 
test as a completely normal one, especially as the variations in specific gravity in the two-hourly specimens are marked; there is a good response of water excretion to dinner and supper, the salt elimination is adequate, and the night urine shows neither increased amount nor lowered specific gravity. Successive advances in impairment of renal function are seen in the tests depicted in Table 20, Chart 5, and in Table 21, Chart 6.

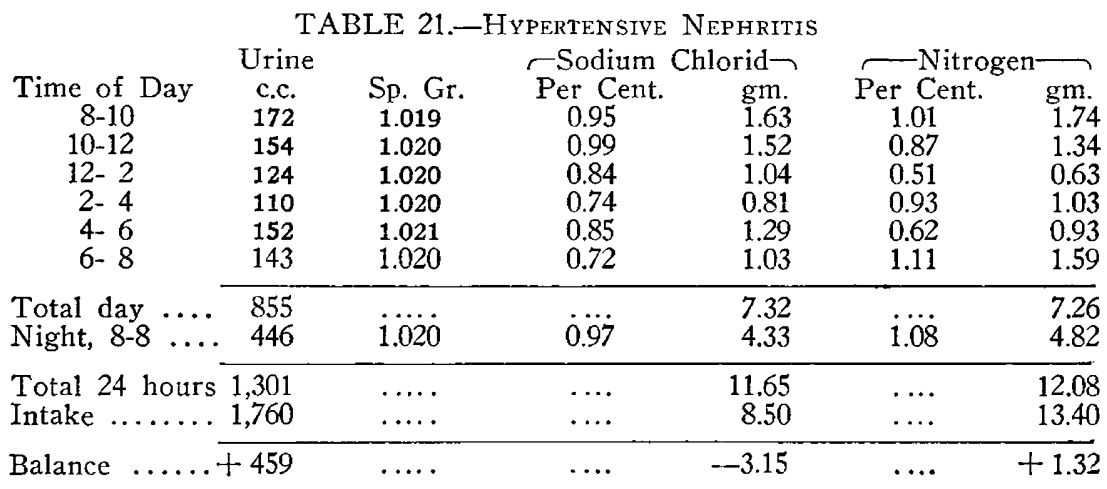

Impression (the figures correspond with Chart 6): Nephritic test meal in a case of marked hypertensive nephritis. The fixation of specific gravity at a level somewhat higher than that seen in more advanced cases of hypertensive nephritis is very striking.

In the former of these, the specific gravity fluctuates between narrower limits than normal, there is distinct polyuria, the night urine is increased in amount and shows a low specific gravity and low nitrogen concentration. In the second case, the fixation of specific gravity is striking, though its level is higher (1.020) than that seen in the more advanced stages of the disease (1.010). This phenomenon is not commonly seen in nephritic individuals, and when it does occur, the possibility of renal congestion, depending on myocardial decompensation, must be kept in mind. However, the oliguria, coupled with a very low salt output and a high nitrogen excretion in cardiac cases, usually distinguishes such urines from one another without difficulty. The changes that are brought about in the urine by the functional impairment occurring in the course of development of an interstitial nephritis may be formulated in the following manner, though this order of events will not pertain in every case. In the main, it portrays facts as they are usually encountered:

1. Nocturnal polyuria (over 400 c.c.).

2. Tendency to total polyuria (the volume of urine equals or surpasses the quantity of liquids ingested). 
3. Fixation of specific gravity, gradually becoming more intense, until it is absolute and the specimens only show a maximum variation of 1 or 2 degrees. In the earlier stages, specific gravity may be fixed at a higher level than later.

4. Fixation of the two-hourly quantities of urine eliminated. That is, the usual polyuric response to meals is absent.

5. The quantity of night urine may diminish to within normal limits. Such night urines, however, are characterized by a low specific gravity and a low percentage of nitrogen.

6. A retention of both salt and nitrogen, which may become very marked.

Cases Simulating the Mode of Urinary Output Found in Advanced Nephritis.-In cases of hypertrophied prostate and its sequelae, of pyelonephritis, polycystic kidney and severe anemia, whether of the primary or secondary type, results are obtained with the test meal which are similar in every detail to those that have been described for advanced instances of contracted kidney. These are shown in Charts $9,10,11$ and 12 .

These observations make it clear that the low fixed specific gravity, etc., so characteristic of advanced cases of hypertensive nephritis may be reproduced by widely different causes. These may be summarized as follows:

1. Causes in the urinary passages, pyelitis, cystitis, hypertrophied prostate.

2. Causes in the blood; marked anemia.

3. Causes in the kidney itself (organic as well as functional lesions), pyelonephritis, polycystic lidney, chronic interstitial nephritis (both primary and secondary contracted kidney), diabetes insipidus.

It is true that changes resembling those mentioned above are found in congestion of the kidney and in chronic diffuse nephritis (before the picture of contracted kidney supervenes), although there are certain variations from the type just depicted that are of material aid in diagnosing and treating these cases that will be detailed a little further on. It is interesting to note how very different the influences are that result in similar changes in function. From the functional change alone one would be warranted in considering the prognosis grave. Hence it must be emphasized that, when such evidence of functional damage is obtained, searching examination must be made for extrarenal causes or curable renal lesions, especially a hypertrophied prostate or other cause for urinary obstruction. Prognosis and therapy will depend largely on the cause of the functional impairment, not on its degree. The removal of a hypertrophied 


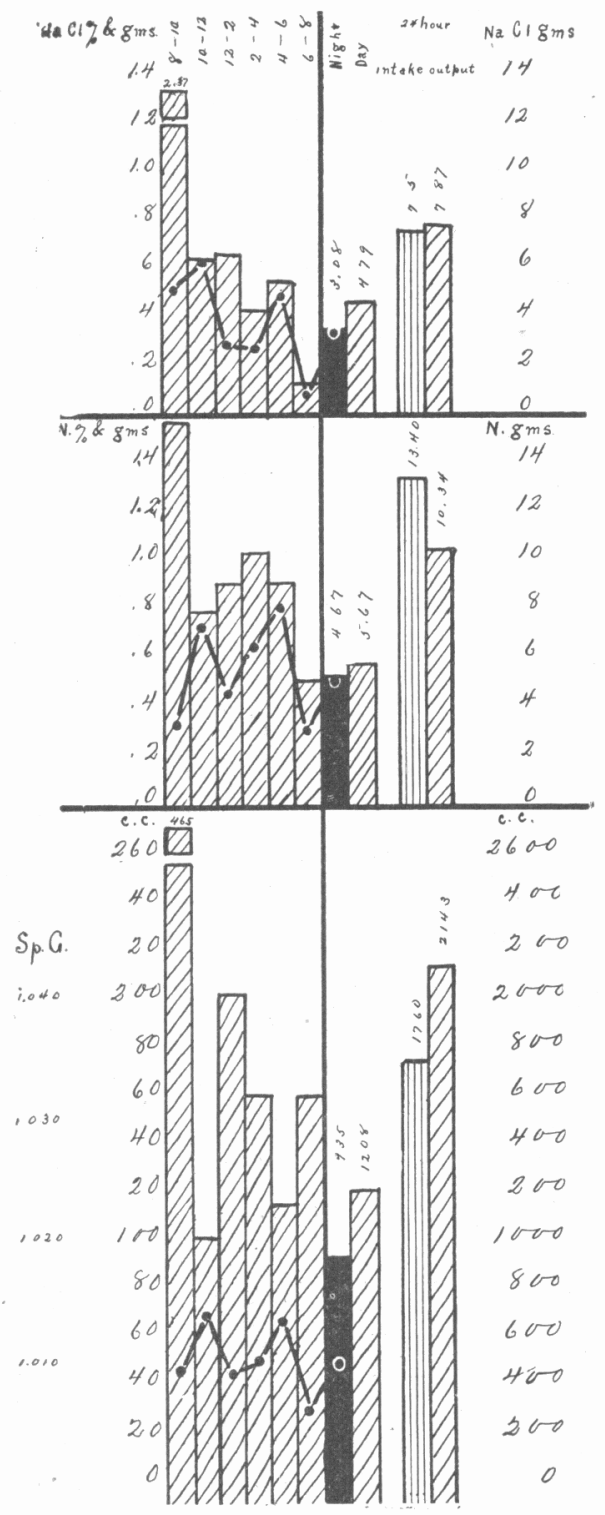

Chart 5

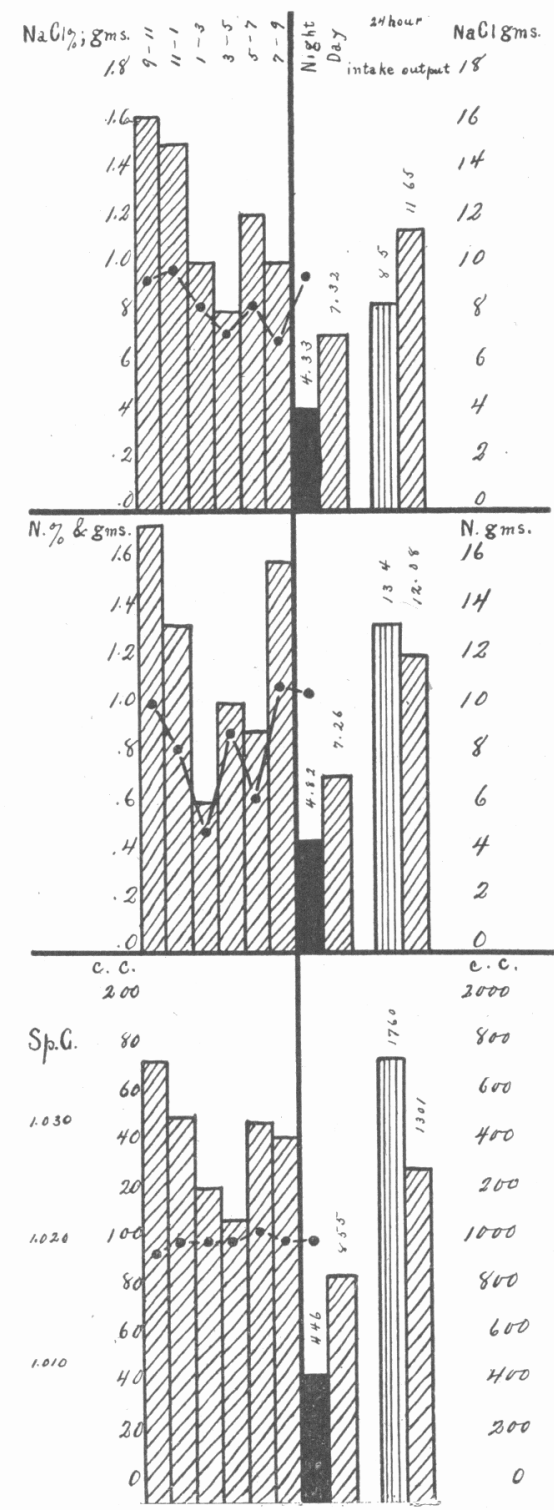

Chart 6

Chart 5.-Early case of hypertensive nephritis. (Systolic blood pressure, 160-190. Urine shows faint trace of albumin and a few granular casts.) Nephritic test meal here shows a tendency towards the fixation of specific gravity and distinct nocturnal polyuria.

Chart 6.-Marked hypertensive nephritis. (Blood pressure, 180. Urine shows trace of albumin and a few hyaline casts.) Nephritic test meal shows markedly fixed specific gravity at a somewhat higher level than the more extreme cases shown in Charts 7 and 8 . 


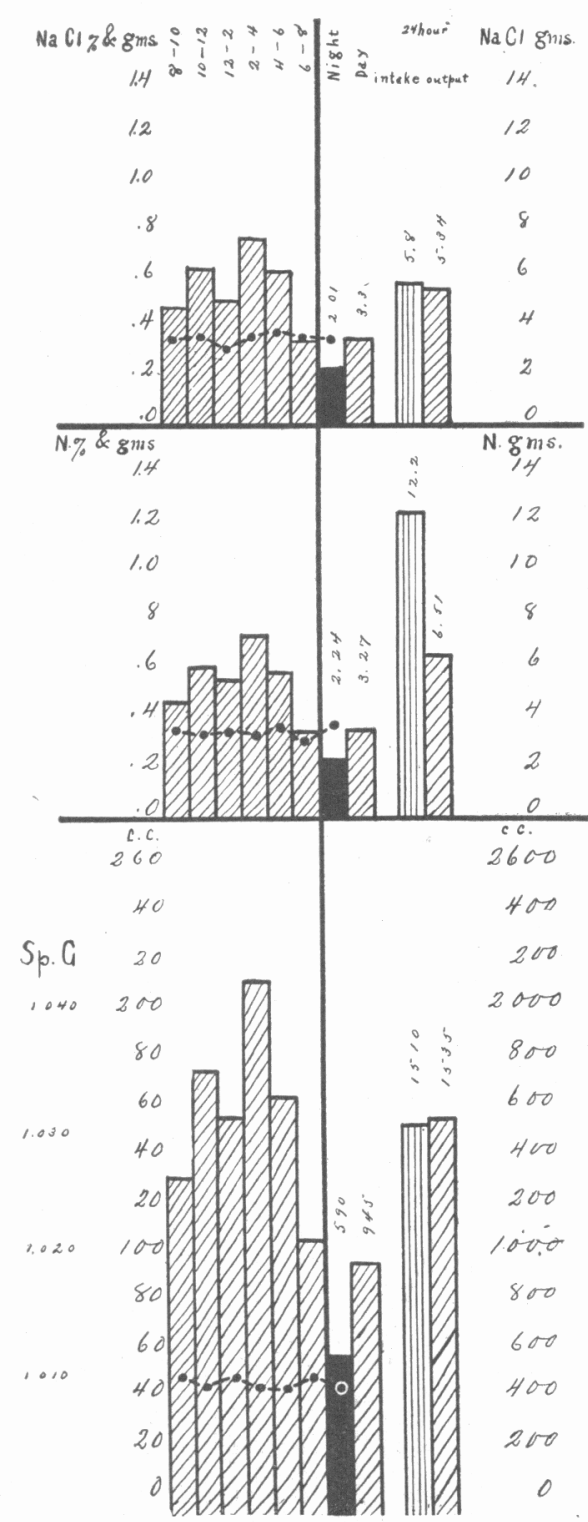

Chart 7

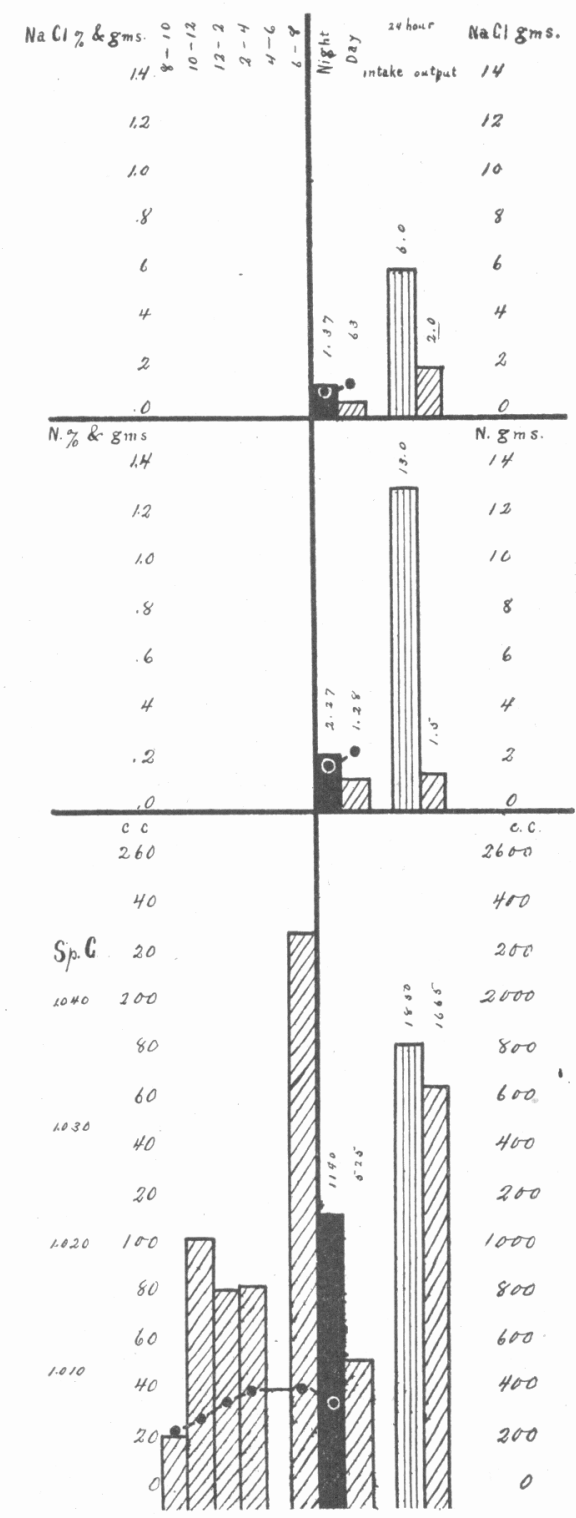

Chart 8

Chart 7.-Advanced hypertensive nephritis. (Systolic blood pressure in the neighborhood of 200 . Albumin to $3 \mathrm{gm}$. per liter; few granular and hyaline casts; albuminuric retinitis.) Nephritic test meal shows markedly fixed specific gravity at the level of about 1.010 and marked fixation of the percentage quantities of salt and nitrogen. This test was repeated on two subsequent occasions and exactly the same figures obtained. There is evidently a retention of salt and nitrogen, low specific gravity and a low concentration of nitrogen at night with only slight nocturnal polyuria.

Chart 8.-Extreme hypertensive nephritis. (Systolic blood pressure, 200-235. Urine contains trace of albumin and a few granular casts). Nephritic test meal accentuates all the conditions found in Chart 7 to an extreme degree. 
prostate, the subsidence of a pyelitis, the cure of a severe anemia, may be followed by great functional improvement, while a similar test meal picture in chronic nephritis or polycystic kidney would indicate a speedy fatal termination.

Renal Congestion (Myocardial Insufficiency).-With extreme acute myocardial decompensation very characteristic results are obtained with the test meal (Table 22, Chart 13):

1. Specific gravity markedly fixed at the level of about 1.020 .

2. A diminished output of salt. The low percentage figures for sodium chlorid are striking.

3. An adequate nitrogen output. The very high concentration of nitrogen is in marked contrast to that of the salt.

4. An oliguria.

5. A night urine normal in character.

The oliguria, good nitrogen excretion, normal night urine and high fixed specific gravity readily distinguish this condition from the advanced cases of chronic interstitial nephritis.

The same characteristics as those shown above are found in the patients with myocardial insufficiency persisting over a long period (Table 23, Chart 14). Similar results are also obtained in those cases in which insufficient heart action may be considered to be "slight," that is, when it is only manifested by dyspnea on exertion or slight cyanosis. Thus, in this class of patients, since the kidney is so sensitive in its reaction to circulatory disturbances, the test meal becomes a valuable means of estimating the degree of myocardial insufficiency which may exist.

TABLE 22.-Urine in Extreme Cardiac Decompression

\begin{tabular}{|c|c|c|c|c|c|c|}
\hline \multicolumn{3}{|c|}{ Urine } & \multicolumn{2}{|c|}{-Sodium Chlorid } & \multicolumn{2}{|c|}{ 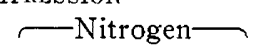 } \\
\hline $\begin{array}{c}\text { Time of Day } \\
8-10 \\
10-12 \\
12-2 \\
2-4 \\
4-6 \\
6-8\end{array}$ & $\begin{array}{l}\text { c.c. } \\
61 \\
\mathbf{5 2} \\
\mathbf{6 5} \\
\mathbf{5 5} \\
30 \\
35 \\
\end{array}$ & $\begin{array}{l}\text { Sp. Gr. } \\
1.018 \\
1.020 \\
1.019 \\
1.018 \\
1.020 \\
1.021\end{array}$ & $\begin{array}{c}\text { Per Cent. } \\
0.20 \\
0.24 \\
0.26 \\
0.27 \\
0.26 \\
0.40\end{array}$ & $\begin{array}{l}\text { gm. } \\
0.12 \\
0.12 \\
0.17 \\
0.15 \\
0.07 \\
0.14\end{array}$ & $\begin{array}{c}\text { Per Cent. } \\
1.52 \\
1.83 \\
1.73 \\
1.65 \\
1.61 \\
1.80\end{array}$ & $\begin{array}{l}\mathrm{gm} . \\
0.93 \\
0.95 \\
1.12 \\
0.90 \\
0.48 \\
0.63\end{array}$ \\
\hline $\begin{array}{l}\text { Total day } \\
\text { Night, 8-8 }\end{array}$ & $\begin{array}{l}298 \\
275\end{array}$ & 1.021 & 0.31 & $\begin{array}{l}0.77 \\
0.85\end{array}$ & 1.85 & $\begin{array}{l}5.01 \\
5.07\end{array}$ \\
\hline $\begin{array}{l}\text { Total } 24 \text { hours } \\
\text { Intake } \ldots \ldots \ldots\end{array}$ & $\begin{array}{l}573 \\
570 \\
\end{array}$ & $\begin{array}{l}\cdots . . \\
\cdots \cdots \\
\cdots\end{array}$ & $\begin{array}{l}\cdots \\
\cdots \\
\cdots\end{array}$ & $\begin{array}{l}1.62 \\
5.00\end{array}$ & $\begin{array}{l}\ldots \\
\ldots\end{array}$ & $\begin{array}{l}10.08 \\
12.00\end{array}$ \\
\hline
\end{tabular}

Impression (the figures correspond with Chart 13): Nephritic test meal in an extreme case of cardiac decompensation. Note the high concentration of nitrogen as compared to the low figures for salt. There is distinct oliguria. (The water output should be higher as general anasarca was present.) 
TABLE 23.-Urine in Marked Cardiac Decompensation

\begin{tabular}{|c|c|c|c|c|c|c|}
\hline $\begin{array}{c}\text { Time of Day } \\
8-10 \\
10-12 \\
12-2 \\
2-4 \\
4-6 \\
6-8\end{array}$ & $\begin{array}{c}\text { Urine } \\
\text { c.c. } \\
65 \\
53 \\
51 \\
49 \\
37 \\
57\end{array}$ & $\begin{array}{l}\text { Sp. Gr. } \\
1.025 \\
1.024 \\
1.024 \\
1.025 \\
1.024 \\
1.021\end{array}$ & - Sodium & $\begin{array}{c}\text { Chlorid } \longrightarrow \\
\text { gm. }\end{array}$ & Per Cent. & $\mathrm{gm}_{\text {gm. }}$ \\
\hline $\begin{array}{l}\text { Total day } \ldots . \\
\text { Night, } 8-8 \ldots\end{array}$ & $\begin{array}{l}312 \\
172\end{array}$ & 1.021 & $\begin{array}{l}0.58 \\
0.42\end{array}$ & $\begin{array}{l}1.81 \\
0.72\end{array}$ & $\begin{array}{l}1.53 \\
1.67\end{array}$ & $\begin{array}{l}4.77 \\
2.87\end{array}$ \\
\hline $\begin{array}{l}\text { Total } 24 \text { hours } \\
\text { Intake ....... }\end{array}$ & $\begin{array}{l}484 \\
995\end{array}$ & $\begin{array}{l}\cdots \cdots \\
\cdots \cdots\end{array}$ & $\cdots$ & $\begin{array}{l}2.53 \\
7.00\end{array}$ & $\cdots$ & $\begin{array}{l}7.64 \\
9.40\end{array}$ \\
\hline Balance..... & +511 & $\cdots$ & ... & +4.47 & $\cdots$ & 1.76 \\
\hline
\end{tabular}

Impression (the figures correspond with Chart 14.) Nephritic test meal in an individual with marked cardiac decompensation which has persisted for some time. The same results as in Table 19 may be noted.

Hypertensive nephritis complicated by myocardial decompensation is a symptom complex met with so frequently that it demands attention in a study of this kind. Table 24, Chart 19, shows the results of a test on a case of this sort. It is very apparent that in this instance the characteristics of myocardial decompensation are more in evidence than those of hypertension or nephritis. In other words, the congestion proves itself the predominating factor in influencing renal activity. This is of interest in connection with von Noorden's ${ }^{4}$ statement of the variability of the specific gravity in chronic interstitial nephritis, in contrast with the usual conception of low, fixed specific gravity under these circumstances. Low salt, contrasted with high nitrogen concentration and a rather high specific gravity in the urine of patients with a systolic blood pressure in the neighborhood of 200 and marked cardiac insufficiency, has been demonstrated in five cases. However, instances have also been met with in which the effects of the passive congestion cannot "break through" the barrier imposed by the contracted kidney. One example of this kind was found in M. C., aged 50, a valet, whose systolic blood pressure varied between 235 and 180; the heart was the seat of an aortic insufficiency of luetic origin, and gave evidences of marked dilatation and hypertrophy; there were signs of extreme cardiac decompensation, marked edema, fluid in the pleural and peritoneal cavities, intense dyspnea and cyanosis. The cardiac and renal diagnoses were confirmed at necropsy. The immediate cause of death in this case was evidently passive congestion, resulting from weak heart action, and yet the specific gravity of the daily specimens of urine in the course of thirty-six days varied between 1.012 and 1.014, with the exception of one occasion, when it rose to 1.019 . 


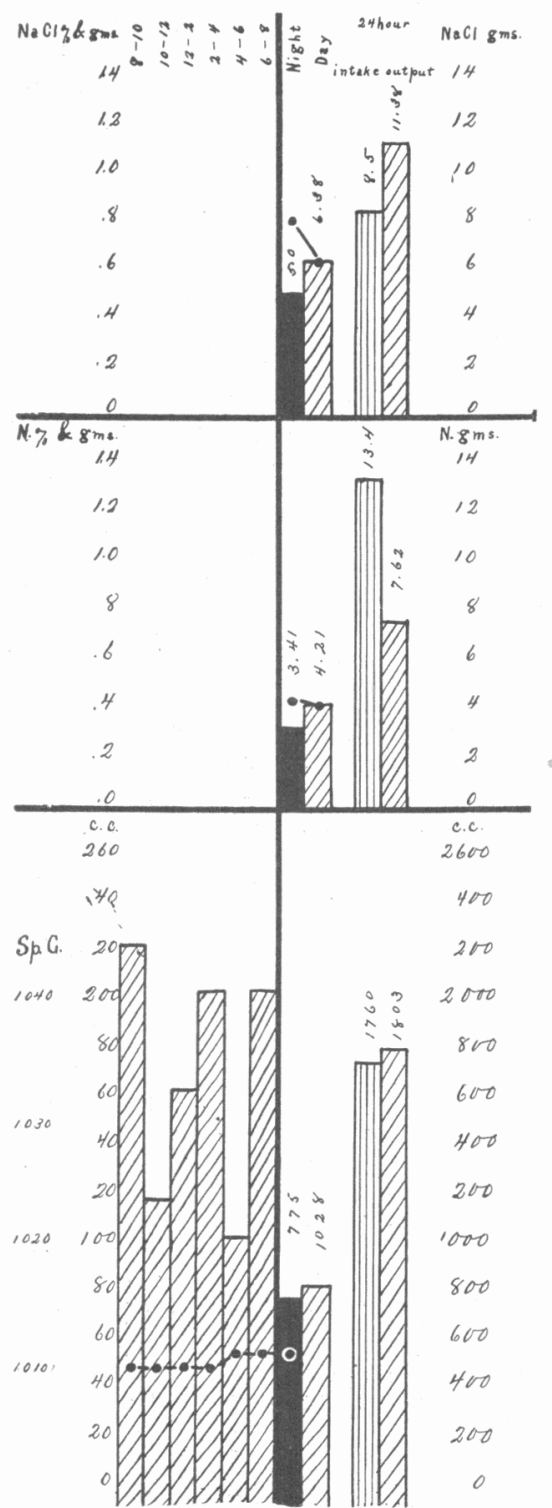

Chart 9

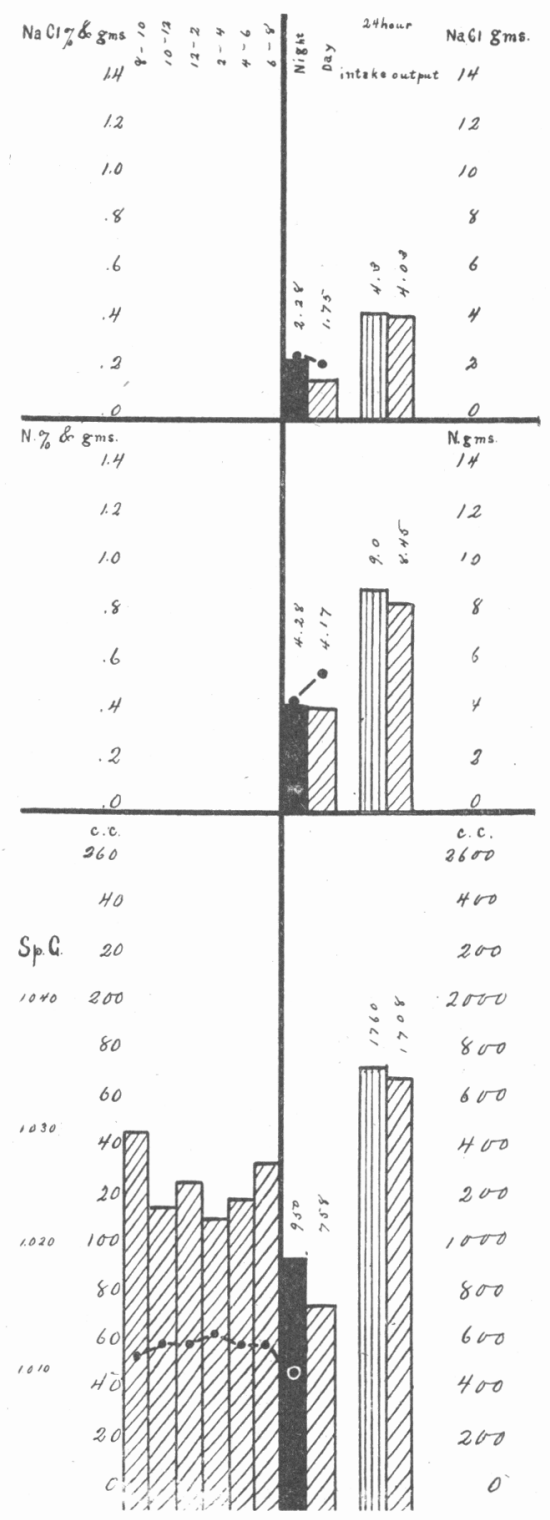

Chart 10

Chart 9.-Cystitis; pyelitis; hypertrophied prostate.

Chart 10.-Pyelonephritis. 


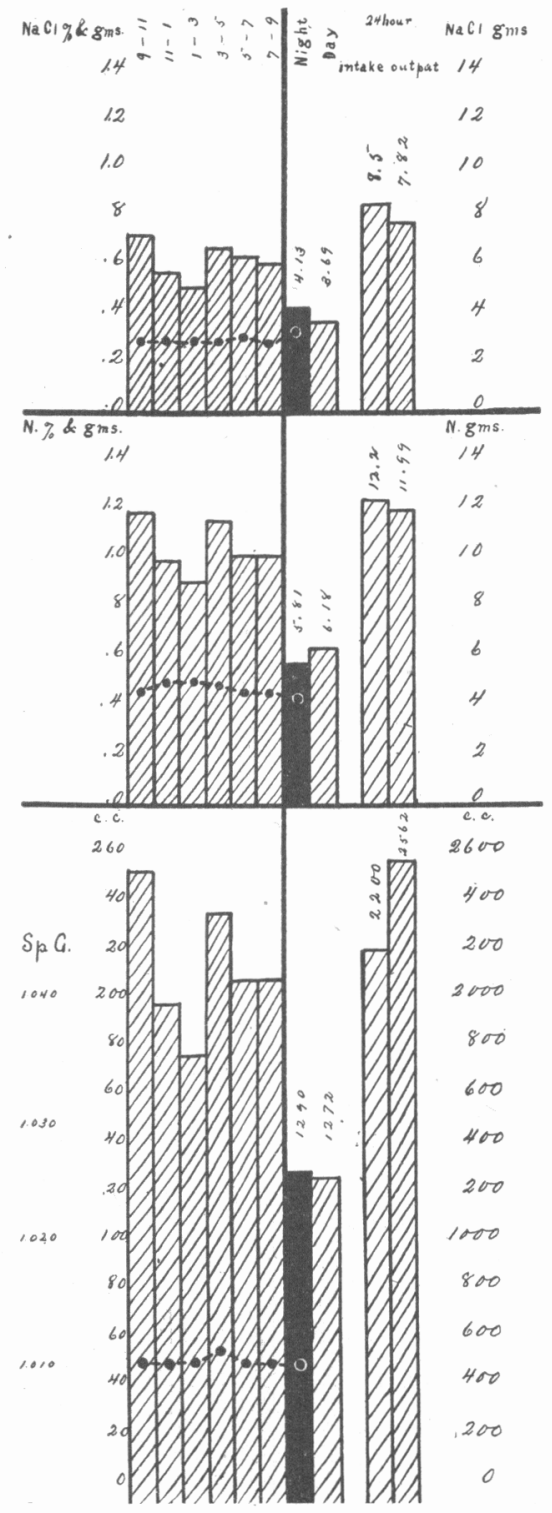

Chart 11

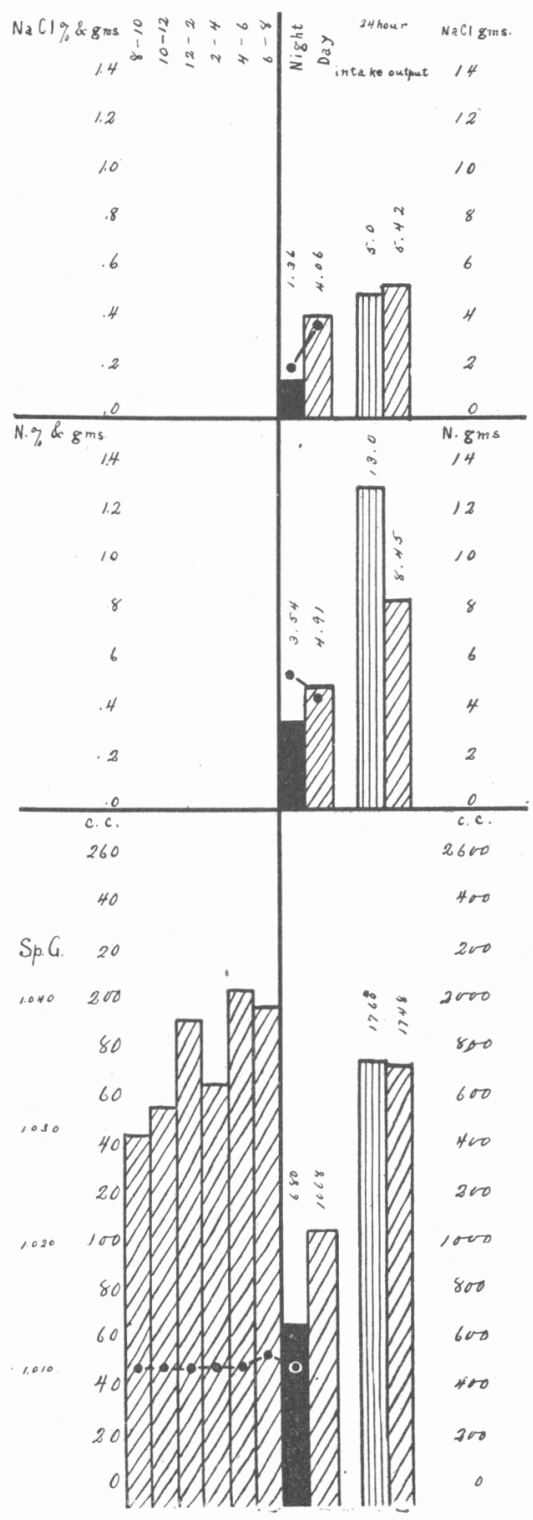

Chart 12

Chart 11.-Polycystic kidney.

Chart 12.-Marked anemia. Hb., 44 per cent.; red blood cells, 2,240,000. 


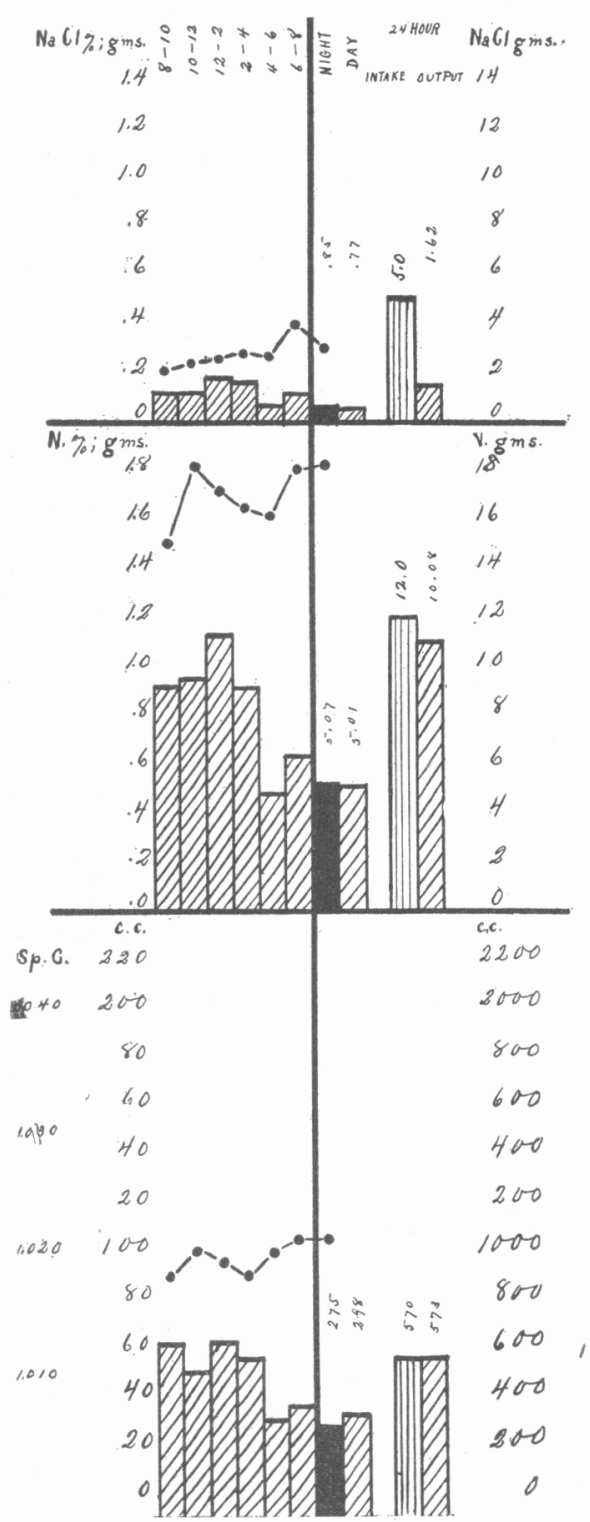

Chart 13

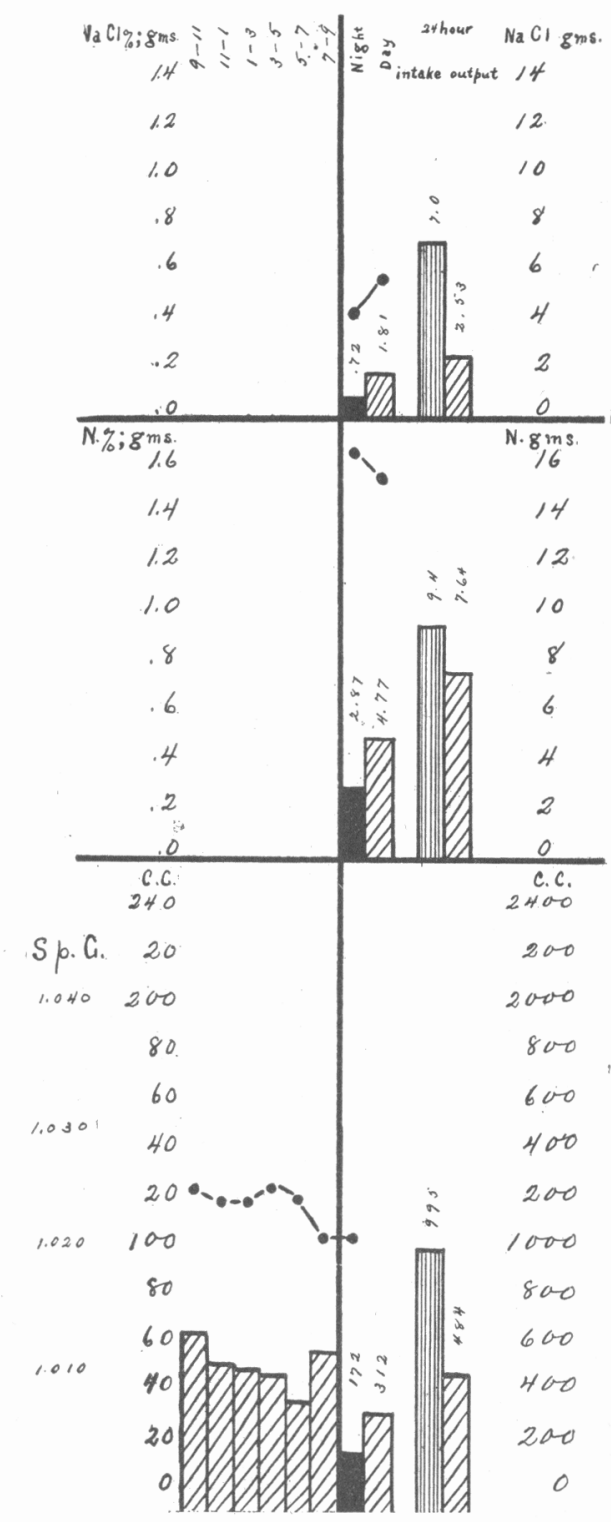

Chart 14

Chart. 13.-Extreme cardiac decompensation. Nephritic test meal shows a low water output with a fixed specific gravity at about 1.020 . (The water output should be higher, as general anasarca was present.) The nitrogen percentage is extremely high and nitrogen elimination is adequate. There is a retention of salt and a very low concentration of salt in the urine.

Chart 14.-Marked cardiac decompensation. Nephritic test meal shows the same changes as Chart 13 , but to a less degree. 


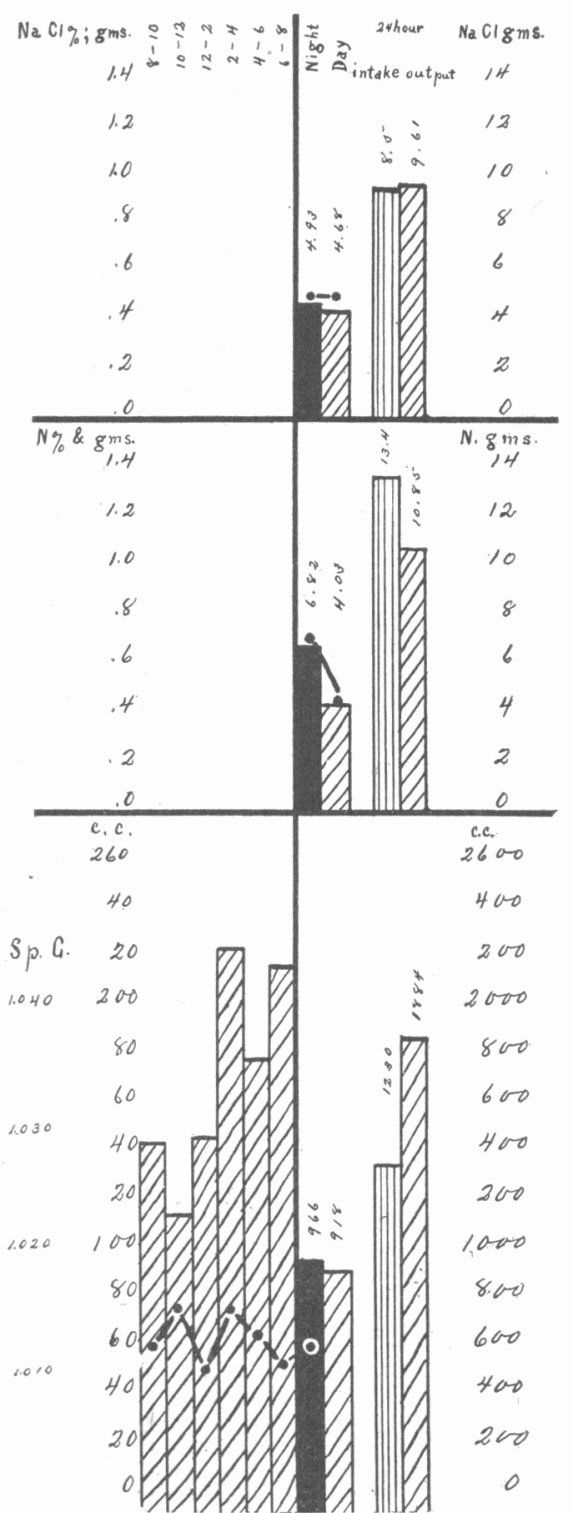

Chart 15

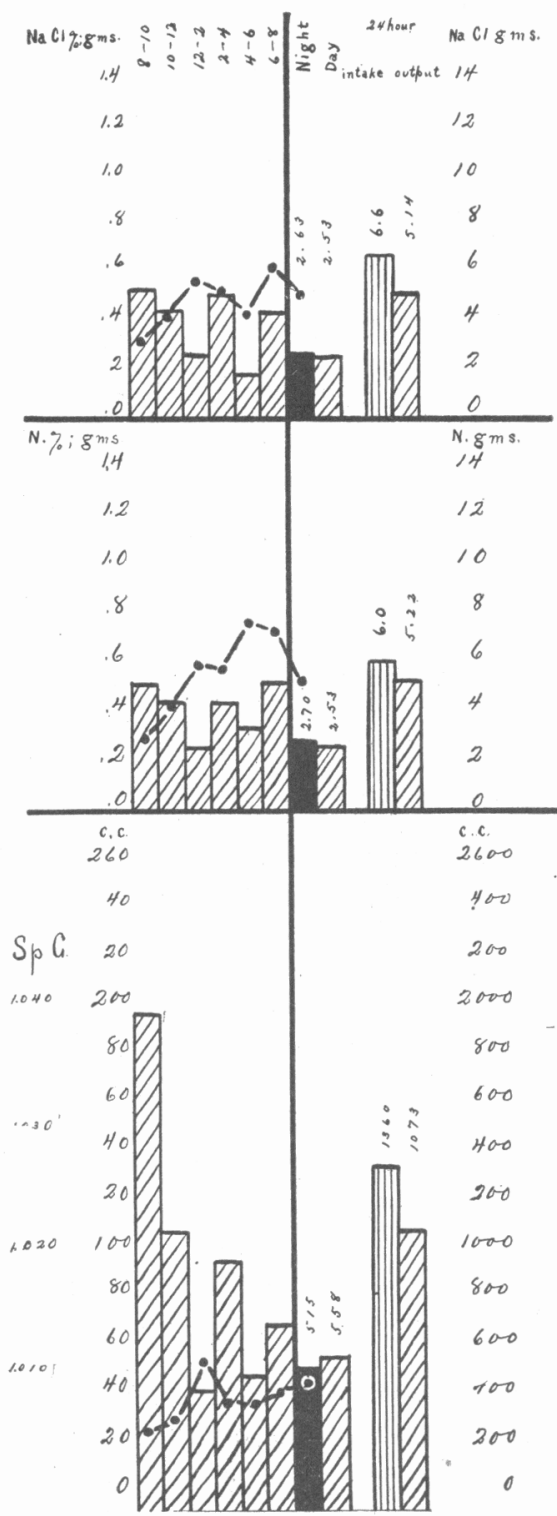

Chart 16

Chart 15.-Cardiac decompensation while eliminating edematous fluid. Nephritic test meal shows a low specific gravity, nocturnal polyuria and low specific gravity at night. Salt and nitrogen eliminations are normal.

Chart 16.-Myocardial insufficiency - after an apparently complete restoration to normal condition. Nephritic test meal shows a low, rather fixed specific gravity, a slight grade of nocturnal polyuria and a very low specific gravity in the night urine. 
TABLE 24.--Hypertensive Nephritis Complicated by Myocardial INSUFFICIENCY

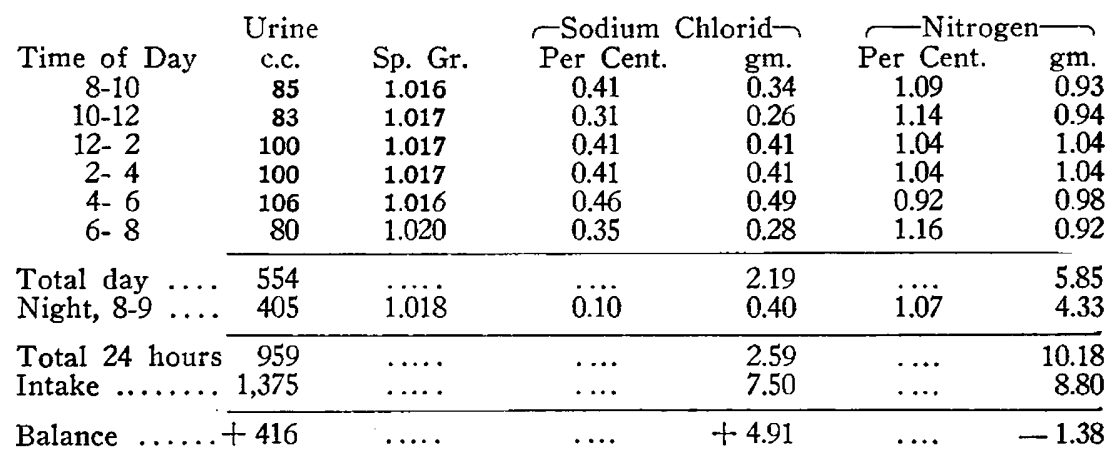

Impression (the figures correspond with Chart 19): Test meal curve in a case of hypertensive nephritis complicated by myocardial insufficiency. The low salt and high nitrogen elimination are characteristic of renal congestion, as is the high fixed specific gravity. It shows how the influence of renal congestion may "break through" the functional picture presented in hypertensive nephritis.

It becomes apparent that when the combination of cardiac insufficiency and hypertensive nephritis exists, the urinary symptoms of either may predominate. In the experience presented here, the characteristic urine of a passively congested kidney has been most often found. However, the number of cases studied is too small to insist on this point. Krehl, ${ }^{14}$ on the other hand, believes that under these circumstances, in spite of renal congestion, the specific gravity of the urine is low and its volume high.

After cardiac compensation has again become established in cases of uncomplicated heart disease, the urinary curve of the test meal is much changed. During the period of elimination of edema (Table 25, Chart 15), as might be expected from the polyuria existing at this time, the following characteristics are found:

1. Specific gravity low and somewhat fixed.

2. Nitrogen elimination normal.

3. Salt and water excretion exceed the amount ingested.

4. The night urine is increased in amount, has a low specific gravity and low percentage of nitrogen.

Subsequently, all the edematous fluid having been eliminated, the urinary function does not assume the normal type, as is usually supposed, but exhibits certain decided peculiarities (Table 26, Chart 16) :

1. Low, moderately fixed specific gravity.

2. Normal nitrogen and water output.

14. Krehl: Die Erkrankungen d. Herzmuskels, 1913, p. 448. 
3. Slightly diminished salt excretion.

4. The night urine may or may not be increased in quantity; its specific gravity and nitrogen concentration are low.

TABLE 25.-Cardiac Decompensation Recovery, Eliminating Edema

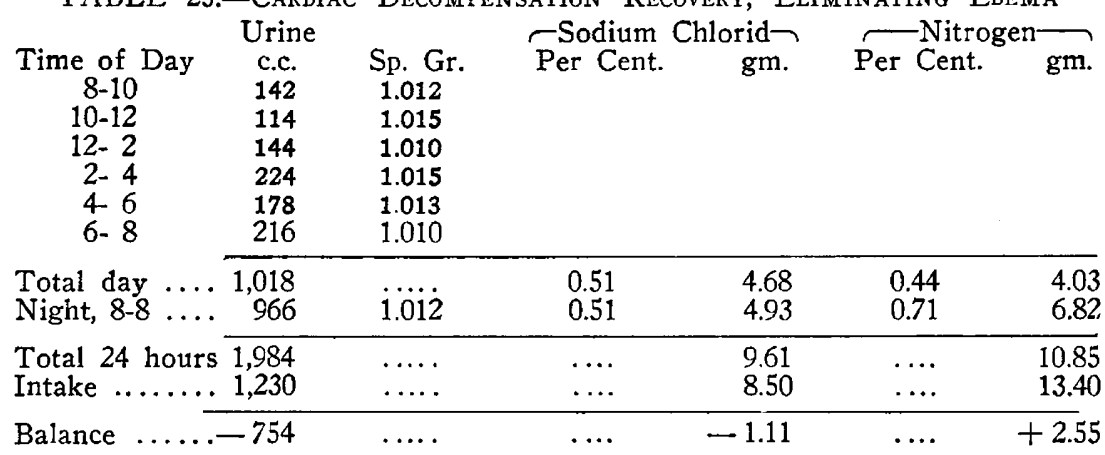

Impression (the figures correspond with Chart 15): Nephritic test meal from a case of cardiac decompensation while eliminating edema fluid. Note the low and rather fixed specific gravity, the elimination of large amounts of salt and fluid and a night urine increased in quantity with a low specific gravity and a low percentage of nitrogen.

\begin{tabular}{|c|c|c|c|c|c|c|}
\hline \multirow{2}{*}{$\begin{array}{c}\text { TABLE } 26 . \\
\text { Time of Day } \\
8-10 \\
10-12 \\
12-2 \\
2-4 \\
4-6 \\
6-8\end{array}$} & \multirow{2}{*}{$\begin{array}{c}\text { Ful. } \\
\text { Urine } \\
\text { c.c. } \\
198 \\
108 \\
41 \\
95 \\
46 \\
70\end{array}$} & \multirow{2}{*}{$\begin{array}{c}\text { Cardiac C } \\
\text { Sp. Gr. } \\
1.005 \\
1.006 \\
1.011 \\
1.009 \\
1.009 \\
1.010 \\
\end{array}$} & \multirow{2}{*}{$\begin{array}{c}\text { Compensation } \\
\text { - Sodium } \\
\text { Per Cent. } \\
0.27 \\
0.42 \\
0.58 \\
0.54 \\
0.43 \\
0.61\end{array}$} & \multirow{2}{*}{$\begin{array}{c}\text { FollcwiNG } \\
\text { Chlorid- } \\
\text { gm. } \\
0.54 \\
0.45 \\
0.24 \\
0.51 \\
0.20 \\
0.43\end{array}$} & \multicolumn{2}{|c|}{$\begin{array}{c}\text { DECOMPENSATION } \\
\overbrace \text { Nitrogen- }\end{array}$} \\
\hline & & & & & $\begin{array}{c}\text { Per Cent. } \\
0.27 \\
0.41 \\
0.60 \\
0.59 \\
0.79 \\
0.74\end{array}$ & $\begin{array}{l}\text { gm. } \\
0.53 \\
0.44 \\
0.24 \\
0.43 \\
0.36 \\
0.52\end{array}$ \\
\hline $\begin{array}{l}\text { Total day } \\
\text { Night, } 8-8\end{array}$ & $\begin{array}{l}558 \\
515\end{array}$ & 1.011 & 0.51 & $\begin{array}{l}2.37 \\
2.63\end{array}$ & 0.53 & $\begin{array}{l}2.52 \\
2.70\end{array}$ \\
\hline $\begin{array}{l}\text { Total } 24 \text { hours } \\
\text { Intake ....... }\end{array}$ & $\begin{array}{l}1,073 \\
1,360\end{array}$ & $\ldots \ldots$ & $\begin{array}{l}\cdots \\
\cdots\end{array}$ & $\begin{array}{l}5.00 \\
6.60\end{array}$ & $\begin{array}{l}\cdots \\
\cdots\end{array}$ & $\begin{array}{l}5.22 \\
6.00\end{array}$ \\
\hline Balance & 87 & ..... & $\cdots$ & +1.60 & $\ldots$ & 0.78 \\
\hline
\end{tabular}

Impression (the figures correspond with Chart 16): Nephritic test meal from an individual with full cardiac compensation following a period of decompensation. The figures show considerable deviation from the normal: low, moderately fixed specific gravity, slightly diminished salt output, nocturnal polyuria with a low specific gravity and low concentration of nitrogen.

This abnormal picture persists for a period of weeks and possibly months, and seems to be a distinct indication that damage has been caused to the kidney by passive congestion which does not disappear immediately when normal circulation is resumed. The urine passed during this period resembles that of advanced interstitial nephritis in many respects, and in observing the low specific gravity from day to day, the clinician is often puzzled in deciding whether such a nephritis really exists or not. 


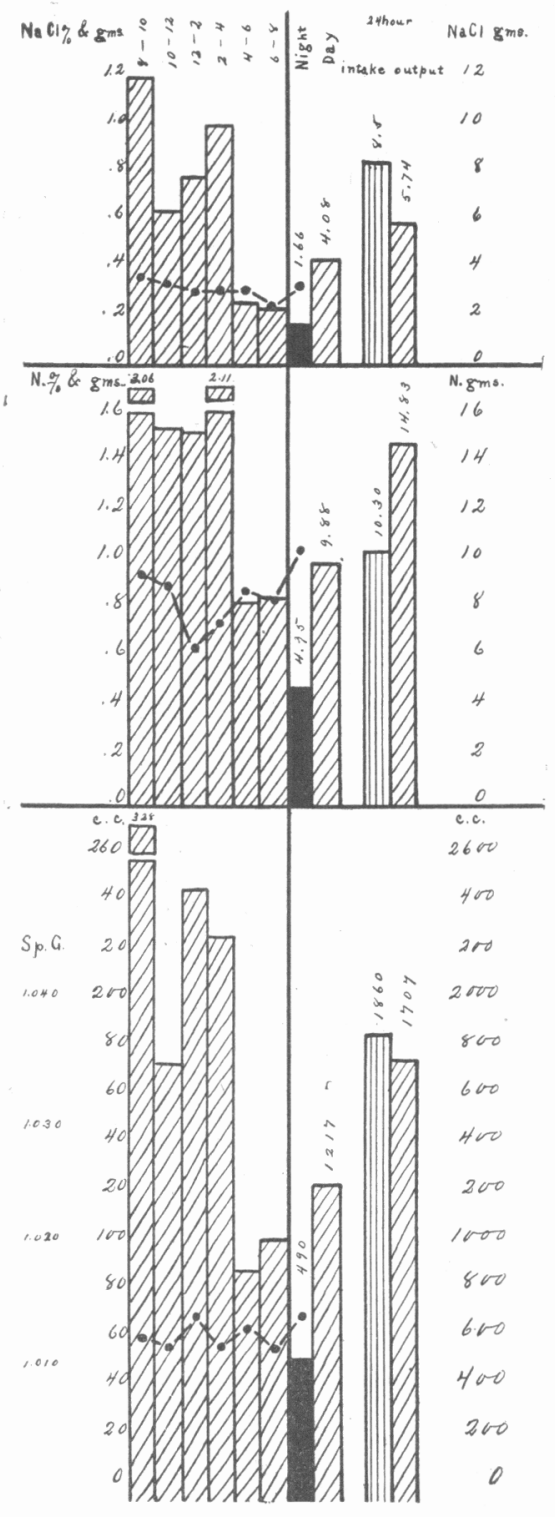

Chart 17

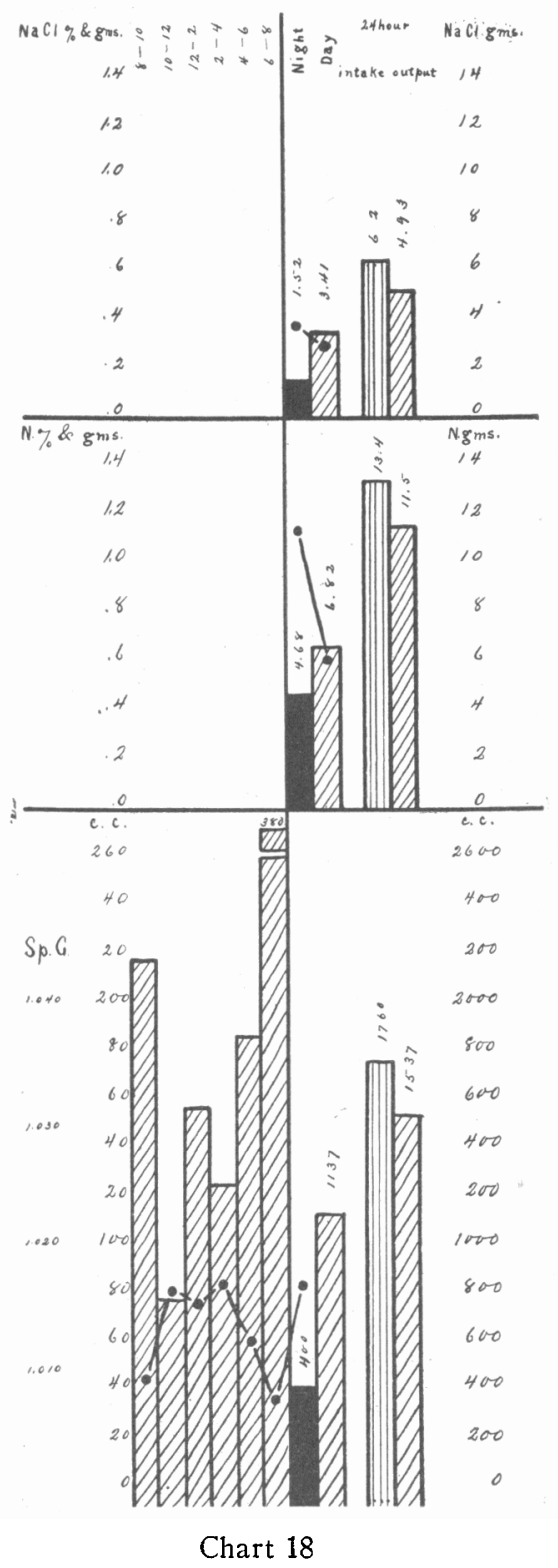

Chart 18

Chart 17.-Chronic diffuse nephritis, with slight hypertension. (Systolic blood pressure, 164 to 174 ; considerable amount of edema; urine shows a marked amount of albumin, blood, granular and hyaline casts.) Nephritic test meal shows an advanced degree of involvement of renal function, very much as in Chart 7 , except that the nitrogen elimination is not reduced.

Chart 18.-Same case as on Chart 17 after an interval of about a month, when the blood pressure had returned to normal, the red blood cells had disappeared from the urine and the edema eliminated. Nephritic test meal shows a condition which approaches the normal and reflects the clinical improvement of the patient when compared with Chart 17 . 


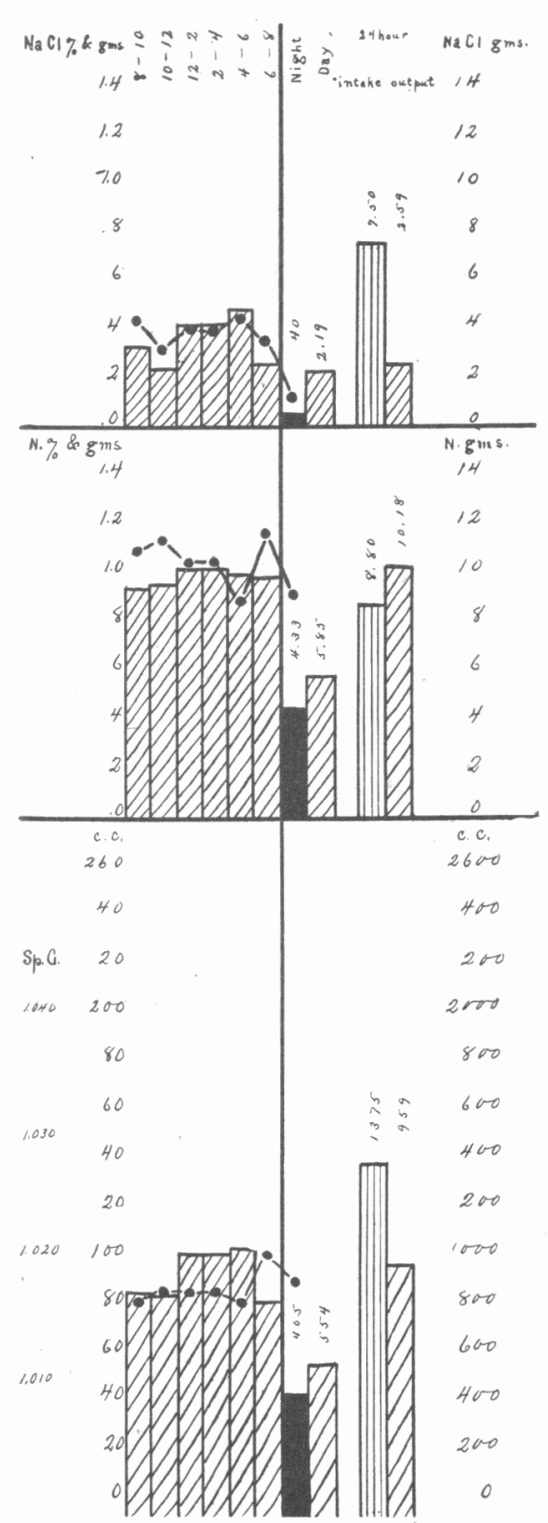

Chart 19

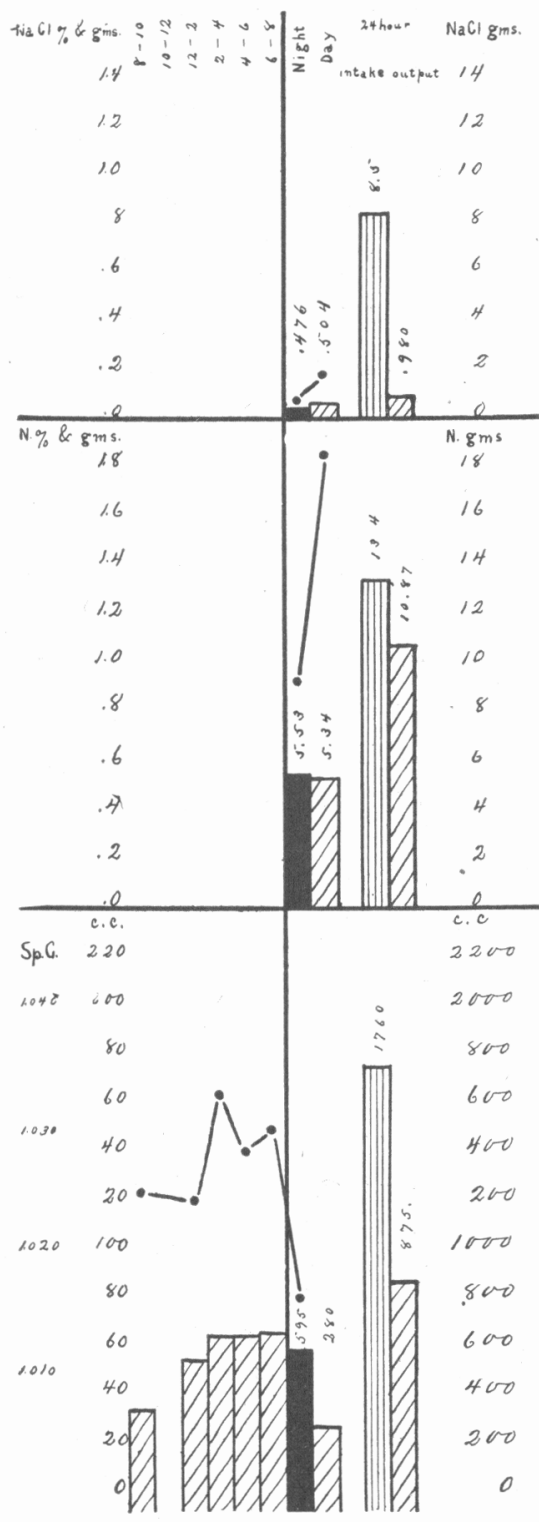

Chart 20

Chart 19.-Myocardial insufficiency, combined with secondary hypertensive nephritis. (Systolic blood pressure, 190 to 230. Marked albuminuria, with many granular casts.) Nephritic test meal shows a result which is decidedly more characteristic of renal congestion than it is of a fairly well advanced nephritis. (Compare with Charts 7 and 13.)

Chart 20.-Chronic diffuse nephritis. Nephritic test meal shows marked salt retention, low specific gravity and low concentration of nitrogen at night, slight nocturnal polyuria and water retention. 
Chronic Diffuse (Parenchymatous) Nephritis.-The trinary findings in nephritis of this type are as variable as the clinical symptoms. At times, clinical and functional tests are in strict accord with one another, and at others they diverge widely. During the period of edema formation, the test meal (Table 27, Chart 20) shows marked salt and water retention, a nocturnal polyuria and a good nitrogen excretion. Such urines bear a great resemblance to those seen in myocardial decompensation, and, in fact, it is at times absolutely impossible to differentiate between the two conditions from these data without having recourse to the physical signs, etc., which usually make the diagnosis an easy one.

While edema is being eliminated, the test meal again shows a marked similarity to cases of passive congestion under the same circumstances. Thus, in Table 28 (compare with Table 25, Chart 15), the amount of urine eliminated is large, the quantity of salt excreted approximates double the intake, and nocturnal polyuria is marked.

TABLE 27.-Chronic Diffuse Nephritis

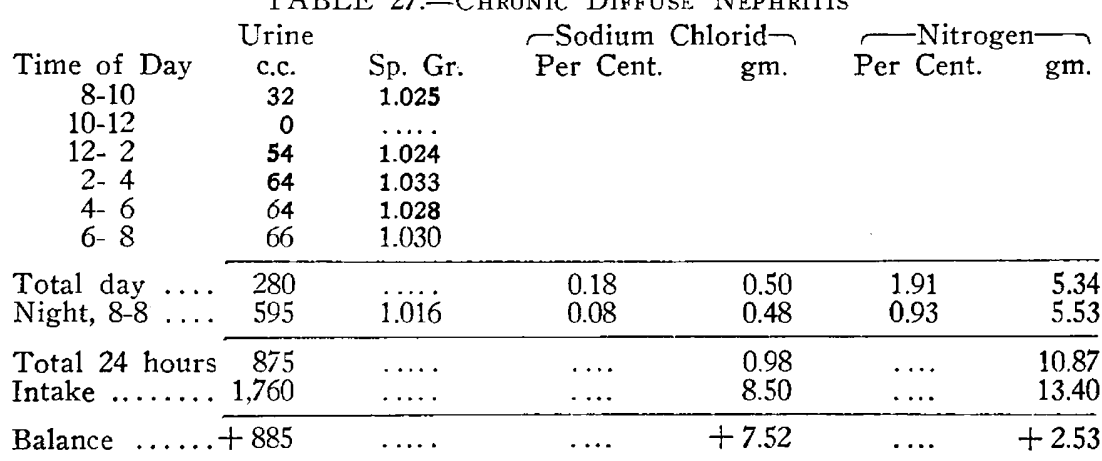

Impression (the figures correspond with Chart 20): Nephritic test meal in a case of chronic diffuse nephritis during the period of edema formation. The marked salt and water retention, the nocturnal polyuria and high nitrogen excretion are characteristic.

TABLE 28.-Chronic Diffuse Nephritis

\begin{tabular}{|c|c|c|c|c|c|c|}
\hline \multirow{8}{*}{$\begin{array}{c}\text { Time of Day } \\
8-10 \\
10-12 \\
12-2 \\
2-4 \\
4-6 \\
6-8\end{array}$} & \multicolumn{2}{|l|}{ Urine } & \multicolumn{2}{|c|}{-Sodium Chlorid } & \multicolumn{2}{|c|}{-Nitrogen- } \\
\hline & c.c. & Sp. Gr. & Per Cent. & $\mathrm{gm}$. & Per Cent. & gm. \\
\hline & 230 & 1.022 & & 2.66 & 1.15 & 2.64 \\
\hline & 130 & 1.025 & 1.08 & 1.40 & 1.42 & 1 \\
\hline & 118 & 1.022 & 1.01 & & 1.21 & 1.43 \\
\hline & 136 & 1.022 & 1.14 & 1.4 & 1.25 & \\
\hline & 96 & 1.020 & 0.7 & & 1.18 & \\
\hline & 108 & 1,014 & 0.8 & 0.87 & 0.89 & 0.96 \\
\hline Total da & 818 & & & 8.24 & & 9.71 \\
\hline Night, 8 & 950 & 1.014 & 0.78 & 7.61 & 0.73 & 7.14 \\
\hline Total 24 hours & 1,768 & & $\ldots$ & 15.85 & .. & 16.85 \\
\hline Intake & 1,760 & $\ldots$. & $\ldots$ & 8.50 & $\cdots$ & 13.40 \\
\hline Balance & 8 & $\ldots$ & .. & -7.35 & & -3.45 \\
\hline
\end{tabular}


Impression: Results of the nephritic test meal in a case of chronic diffuse nephritis, while eliminating edema. Note the large amounts of fluid, salt and nitrogen excreted.

TABLE 29.-Chronic Diffuse Nephritis

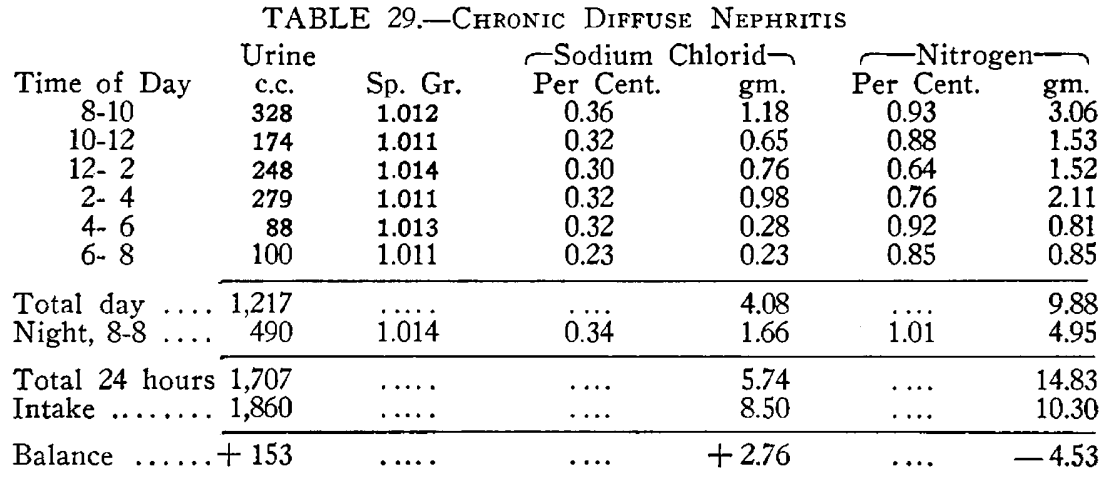

Impression (the figures correspond with Chart 17): Nephritic test meal in a case of chronic diffuse nephritis. A marked involvement of renal function is evident from the low fixed specific gravity.

TABLE 30

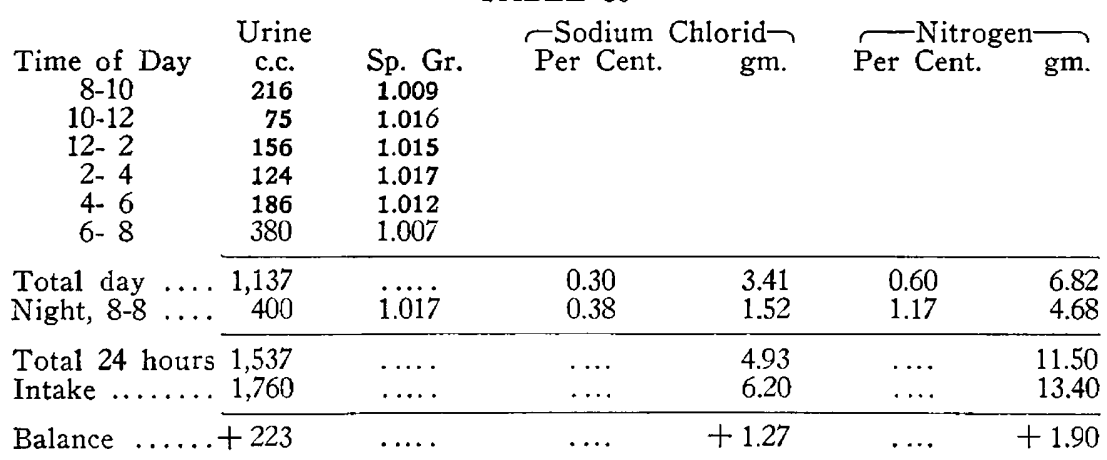

Impression (the figures correspond with Chart 18): Nephritic test meal from the same case as in Table 29. This test was performed about one month later and the marked clinical improvement is reflected in the result which approaches the normal very closely.

An advanced degree of involvement of renal function is seen in Table 29, Chart 17. This is indicated by the low, fixed specific gravity during the night and day time. After rest in bed and other therapeutic measures, the clinical aspect of this case had improved markedly, and in studying Table 30 , Chart 18 , it is seen that this improvement is reflected in a test meal which approximates the normal. The ability of the patient to excrete salt is not well brought out in these tests. In the first, there was salt retention, in the second, there was not. This would have been proved had all the salt offered been taken, since in the early observations recorded it was shown that during the 
first period the salt excretion represented the maximum effort of the kidney in this direction, even when more salt was added to the diet, while in the second it did not. Such pitfalls as these must be considered in the interpretation of the nephritic test meals, but with a little care they may usually be avoided.

One of the most interesting results obtained in this work has been the occasional occurrence of cases showing many of the symptoms of nephritis and little or no change from the normal response to the test meal. (The converse was noted in the cases mentioned under nocturnal polyuria). The following was an instance of this kind:

J. C. (Medical No. 33921), a salesman, aged 47, comes to the hospital complaining of headache; the systolic blood pressure varies between 185 and $200 \mathrm{~mm}$. of mercury; there is considerable cardiac hypertrophy, the apex impulse being in the sixth intercostal space, $13 \mathrm{~cm}$. to the left of the median line; otherwise, the heart shows no abnormalities; the urine contains a trace of albumin and a few hyaline and granular casts. The test meal (Table 31) shows no abnormalities of note. This indicates that the constitutional symptoms of the nephritic complex are well advanced, but that the kidney, so far as its function is concerned, is scarcely affected. Such facts are not only of interest from the pathological point of view, but also of extreme importance in prescribing proper dietary and other therapeutic measures.

Table 31.-Normal Test Meal Curve in Marked Hypertensive Nephritis

\begin{tabular}{|c|c|c|c|c|c|c|}
\hline $\begin{array}{c}\text { Time of Day } \\
8-10 \\
10-12 \\
12-2 \\
2-4 \\
4-6 \\
6-8\end{array}$ & $\begin{array}{c}\text { Urine } \\
\text { c.c. } \\
220 \\
170 \\
154 \\
182 \\
106 \\
34\end{array}$ & $\begin{array}{l}\text { Sp. Gr. } \\
1.017 \\
1.016 \\
1.020 \\
1.018 \\
1.019 \\
1.025\end{array}$ & $\begin{array}{l}\text {-Sodium } \\
\text { Per Cent. }\end{array}$ & $\begin{array}{c}\text { Chiorid- } \\
\text { gm. }\end{array}$ & $\overbrace{\text { Per Cent. }}$ Nitros & $\mathrm{gm}$. \\
\hline $\begin{array}{l}\text { Total day } \ldots \\
\text { Night, } 8-8 \ldots\end{array}$ & $\begin{array}{l}866 \\
283\end{array}$ & 1.028 & $\begin{array}{l}0.50 \\
0.48\end{array}$ & $\begin{array}{l}4.33 \\
1.41\end{array}$ & $\begin{array}{l}0.66 \\
1.04\end{array}$ & $\begin{array}{l}5.72 \\
3.05\end{array}$ \\
\hline $\begin{array}{l}\text { Total } 24 \text { hours } \\
\text { Intake ....... }\end{array}$ & $\begin{array}{l}1,159 \\
1,350\end{array}$ & $\begin{array}{l}\ldots . . \\
\cdots \cdots\end{array}$ & $\begin{array}{l}\ldots \\
\ldots \ldots\end{array}$ & $\begin{array}{l}5.74 \\
8.50\end{array}$ & $\begin{array}{l}\cdots \\
\cdots\end{array}$ & $\begin{array}{l}8.77 \\
9.80\end{array}$ \\
\hline Balance & +191 & & $\cdots$ & +2.76 & $\cdots$ & +1.03 \\
\hline
\end{tabular}

Impression: An approximately normal test meal curve in a case of marked hypertensive nephritis. It shows how, in isolated instances, renal function may be normal in spite of extensive lesions characteristic of interstitial nephritis.

\section{SUMMARY}

The nephritic test meal, as suggested by Hedinger and Schlayer, and elaborated in this paper, has not only proved itself to be an admirable test for renal function, but also in many cases has been of great value in diagnosing cardiac, renal and other conditions. Much pleasure and profit may be derived from a study of diseases of the kidney from this point of view, since it forms a basis for a rational therapy and a stimulus towards keener clinical observation. 
The test is a qualitative one of the mode of urinary function as measured by the specific gravity, salt, nitrogen and water excretion in two-hourly periods during the day, and for a twelve-hour period at night. The normal individual yields specimens with specific gravity figures which vary ten points or more from the highest to the lowest, a night urine high in specific gravity, 1.018 or more, high in its percentage of nitrogen-above 1 per cent.-and small in amount- 400 c.c. or less. The quantities of water, salt and nitrogen excreted approximate the intake. When kidney function becomes involved, the first signs are usually demonstrated in the night urine, the quantity becomes increased; the specific gravity and the nitrogen concentration are lowered. One or all of these changes from the normal may occur. In severe cases of chronic nephritis, an advanced degree of functional inadequacy of the kidney is indicated by a markedly fixed and low specific gravity, a diminished output of both salt and nitrogen, a tendency to total polyuria and a night urine showing an increased volume, low specific gravity and low concentration of nitrogen. Such functional pictures, however, are not confined to nephritis. They are found regularly in many other conditions: pyelitis, cystitis, hypertrophied prostate, marked anemia, pyelonephritis, polycystic kidney, and diabetes insipidus. The cause of diminished renal function, it is clear, must be sought for in many directions-the urinary passages, the blood or the kidney itself. Prognosis and therapy will depend largely on the cause of the fundamental impairment and not on its degree. A divergence between the degree of functional renal involvement and the intensity of the signs and symptoms of nephritis is frequently found, and accentuates the lack of parallelism that there may be between functional and anatomical lesion.

In chronic diffuse (parenchymatous) nephritis, the condition of renal function is characterized by its variability. In these instances, the results of the test meal have proved to be extremely valuable in giving an idea of the status of salt, nitrogen and water excretion, besides the picture of renal efficiency as a whole. The findings in myocardial insufficiency vary according to the activity of the heart. Distinct differences are found with myocardial decompensation and the accumulation of edema, the period of eliminating edema, and subsequently, when cardiac compensation is again fully established, it requires some time before the kidney resumes its normal activity. This intervening period is indicated by a tendency to a low, fixed specific gravity and a nocturnal polyuria. During the period of full 
myocardial decompensation the results of kidney activity are very characteristic, the specific gravity is markedly fixed at the level of about 1.020 , the salt output is diminished, that of nitrogen is high, in marked contrast to the salt, and there is oliguria. When chronic nephritis and cardiac decompensation coexist, as they so often do in hypertensive nephritis, the urine may exhibit the characteristics due to either lesion. The determining factor is probably to be found in the chronic nephritis which may or may not be so far advanced as to present an unchanging barrier to the influence of renal congestion.

Johns Hopkins Hospital. 